NBER WORKING PAPER SERIES

FINANCIAL PATENTING IN EUROPE

Bronwyn H. Hall

Grid Thoma

Salvatore Torrisi

Working Paper 14714

http://www.nber.org/papers/w14714

\author{
NATIONAL BUREAU OF ECONOMIC RESEARCH \\ 1050 Massachusetts Avenue \\ Cambridge, MA 02138 \\ February 2009
}

We are very grateful to Dietmar Harhoff for providing us with updated EPO patent data for this revision of the paper. The paper has also benefited considerably from comments by John Duffy, Dietmar Harhoff, Robert Hunt, Anne Layne-Farrar, Jonathan Squires, Otto Toivanen, participants in the Bank of Finland-CEPR Conference in Helsinki (October 2008) and the AEA Conference in Tokyo (December 2008). The views expressed herein are those of the author(s) and do not necessarily reflect the views of the National Bureau of Economic Research.

NBER working papers are circulated for discussion and comment purposes. They have not been peerreviewed or been subject to the review by the NBER Board of Directors that accompanies official NBER publications.

(C) 2009 by Bronwyn H. Hall, Grid Thoma, and Salvatore Torrisi. All rights reserved. Short sections of text, not to exceed two paragraphs, may be quoted without explicit permission provided that full credit, including $\odot$ notice, is given to the source. 
Financial Patenting in Europe

Bronwyn H. Hall, Grid Thoma, and Salvatore Torrisi

NBER Working Paper No. 14714

February 2009, Revised November 2009

JEL No. G20,L86,O31,O34

\begin{abstract}
$\underline{\text { ABSTRACT }}$
We take a first look at financial patents at the European Patent Office (EPO). As is the case at the US Patent and Trademark Office (USPTO), the number of financial patents in Europe has increased significantly in parallel with significant changes in payment and financial systems. Scholars have argued that financial patents, like other business methods patents, have low value and are owned for strategic reasons rather than for protecting real inventions. We find that established firms in non-financial sectors with diversified patent portfolios own a large share of financial patents at the EPO. However, new specialized technology providers in the financial area also hold a number of such patents. Decisions on the financial patent applications take longer and they are more likely to be refused by the patent office, suggesting greater uncertainty over validity than for other patents. They are also more likely to be opposed, which is consistent with the fact that their other economic value indicators are higher.
\end{abstract}

Bronwyn H. Hall

Dept. of Economics

549 Evans Hall

UC Berkeley

Berkeley, CA 94720-3880

and NBER

bhhall@nber.org

Grid Thoma

University of Camerino, Camerino and

CESPRI, Bocconi University

Via Sarfatti 25

20136

Milano, Italy

grid.thoma@unibocconi.it
Salvatore Torrisi

CESPRI, Bocconi University and

Department of Management

University of Bologna

Via Capo di Lucca 34

40126 Bologna, Italy

torrisi@unibo.it 


\section{Financial Patenting in Europe}

\section{Introduction}

The advent and fast growth of the Internet economy has been accompanied by innovation in traditional forms of financial payments. These changes have been propelled on the one hand by the emergence of new commercial relations conveyed through the Internet which require new and secure modes of payments - e.g. digital market places and e-commerce. On the other hand, traditional markets and industries have experienced the diffusion of new business practices within their procurement and marketing activities (Tufano, 2003; Lerner, 2004).

The potential benign impact of innovation in the payment and financial systems is very high and extends well beyond the banking sector. It is worth remembering that changes in the short term payment and financial systems were at the base - among others - of the commercial revolution in Europe during the fifteenth and sixteenth centuries (Rosenberg and Birdzell, 1986). The relationship between the development of an economy's financial structure - financial instruments, markets and institutions - and economic growth in the modern economy is well documented in the literature (Levine, 1997). More recently, scholars have suggested that innovation in payment and financial systems has some of the features of a General Purpose Technology (GPT) (Hall, 2007). GPTs are technologies characterized by use in a wide range of sectors, the need for complementary investment when adopted, and scope for productivity enhancement in diverse sectors of the economy, leading to increasing returns on both the supply and demand side (Bresnahan and Trajtenberg, 1995).

Here as in most areas, the strengthening of patent coverage can have both positive and negative effects. On the one hand, it can increase the incentive to devote resources to inventive activity. On the other hand, it may discourage or raise the cost of combining and recombining of inventions to make new products and processes, in particular in cumulative innovations such as GPTs and technologies that are part of a standard setting process (see, among others, Scotchmer, 1996; Cohen and Lemley, 2002; Lemley, 2007). These considerations are of particular relevance for financial patents and software and business methods in general (Hall, 2003), due to the importance of standards for technologies enabling web-based interactions and financial transactions, whether conducted via the web or over other telecommunications networks. 
Patenting in this area has increased significantly in the last two decades. According to evidence documented by Hall (2007), 5,393 patents were issued by the United States Patent and Trademark Office (USPTO) in Class 705 (Data Processing: Financial, Business Practice, Management, or Cost/Price Determination) during the decade 1995-2004, corresponding to approximately 2,918 patentees. Patenting in this class accelerated after the key decisions taken by the Courts of Appeals for the Federal Circuit (CAFC) in 1998 which removed most of the exceptions to the patentability of software and other business methods 'as such', that is, methods that are independent of a particular physical embodiment (State Street v. Signature Financial Group 1998, ATT v. Excel Communications 1998). Such patents have proved particularly contentious and subject to litigation, especially those related to financial innovations. For example, Lerner (2006) reported a litigation rate on financial patents twenty-seven times larger than the rate found by Lanjouw and Schankerman (2001) for a sample of all patents.

Even in the U.S., the question of exactly what types of software or business methods may be patented remains controversial. Recently, prompted by a series of Supreme Court decisions, the CAFC decided to reconsider the question of patentable subject matter by scheduling an en banc hearing (before all judges of the Court) to consider an appeal in re Bilski. ${ }^{1}$ A decision issued on October 30, 2008. This decision is viewed as restricting business method and financial patenting at the USPTO to some extent (Managing Intellectual Property, 31 October 2008). In particular, the court found that if an invention relates to a "pure" business method that is not limited to performance on a computer and produces only abstract results such as manipulation of documents, information, or data, it is not patentable subject matter. Moreover the USPTO has already issued clarifying guidelines with respect to business methods (May 15, 2008) and a reform of the patent system is debated at the US Congress.

At the EPO the treatment of software and intangible business methods is different, with these inventions excluded "as such" from patentable subject matter according to the European Patent Convention (Article 52). Nevertheless, when we analyzed a large dataset of EPO patents, we found an increasing number of what appeared to be software-related patents during the 1990s

\footnotetext{
${ }^{1}$ Bernard Bilski's patent application for an invention relating to a method for hedging commodity price risk was rejected by the USPTO as relating to an abstract idea without practical application. The applicants have then appealed to the CAFC.
} 
(Hall, Thoma and Torrisi, 2007). This suggests that, despite the different legal environment, barriers to patenting on software and intangible business methods may have fallen somewhat in Europe as well. This process has been reinforced by some conflicting decisions at the various national European courts and the European Court of Justice. An attempt to clarify EPO practice is currently underway (Managing Intellectual Property, 24 October 2008).

Another notable difference between the two patent systems, US and European, concerns the process for post-grant validity challenges. The US system has two main ways to challenge validity: ex-parte re-examination available to anyone, and litigation over validity, which can only be initiated by a party that has been accused of infringement. ${ }^{2}$ The EPO system relies on an inter partes opposition system which allows third parties to actively provide evidence of prior art that may have been missed during the examination process. Oppositions can be filed by any party at the EPO within 9 months after the patent is granted; in practice they are generally filed on the last eligible day. The input provided by third-party oppositions complement the pre-grant search process conducted by the EPO, especially in new subject matter areas such as software and business methods, where information on prior art is not easily accessible to patent examiners (Janis, 1997; Hall, 2003). As in the U.S., opposition may or may not be followed by litigation, but in this case, the jurisdiction shifts to national courts rather than being European-wide, which makes it a somewhat less attractive option for invalidating a patent.

In the USPTO context the heterogeneity of the actors involved in financial patents can be seen along a number of dimensions (Hall 2007). About 20 per cent of the patentees are alliances or R\&D consortia of financial firms, suggesting the importance of the standards setting process in payment and financial systems. Other patentees are older and larger firms active in nonfinancial and non-software sectors such as oil and gas or machinery. Newer patentees are typically small firms and only three of them - E-Trade, eBay, and Verisign - have more than one billion dollars of revenue annually by 2005 . Another dimension of heterogeneity is the importance of financial patents relatively to the overall portfolio of the patentee: only $0.7 \%$ of patents in this class are granted to firms that specialize in financial patenting, whereas the remaining patents are held by large patentees that operate in a number of other sectors such as

\footnotetext{
${ }^{2}$ There is also an inter-partes re-examination system that was introduced in 1999, but until very recently, it has been rarely used.
} 
Exxon Mobil, Chevron, NCR, Lockheed Martin, Diebold, etc. This picture is quite similar to that of software-related patents, a large proportion of which are held by non-software firms. The small share of patents held by financial institutions in the US is at odds with the importance of these institutions in the creation of financial innovations (Tufano, 2003). Moreover, patent holding firms specialized in licensing and litigating patent awards are the most frequent plaintiffs in patent litigations whereas financial innovators (investment banks, trading exchanges and other financial institutions) are mostly involved as defendants (Lerner, 2006).

Based on this body of evidence, scholars have raised concern about the growing number of financial and business method patents whose average quality is considered low because of the limited examination capacity of the US patent office, the lack of prior art databases (both patent and non-patent literature), and a declining severity of the non-obviousness test in court decisions. Several authors have then suggested that the standard of patentability should be raised especially in subject matters like software and business methods (Barton, 2000; Dreyfuss, 2001; Lunney, 2001; Bessen and Meurer, 2008; Hall, 2007). The CAFC decision in light of the Bilski case and the USPTO clarifying guidelines with respect to business methods may prelude to future potential changes in the patenting rules which add further uncertainty to the uncertainty arising from the ambiguous claims and unclear definition of the boundaries of financial patents and other business method patents. This ambiguity may slowdown the investments on innovation because of hold-up problems that are especially important in the case of sequential innovations, a high risk of involuntary infringement and high litigation costs (Hunt, 2008; Bessen and Meurer, 2008).

Following on the results for the U.S., in this paper we look at the ways in which firms in Europe are dealing with the increase of financial patenting, given the differences they face in patentability in their home markets. The differences between US and European patenting systems - such as (possibly) more thorough search of prior art, the exclusion of software and business methods 'as such' from the patentable subject matter, and the opposition system - offer a fertile ground for examining the ways in which firm patenting strategy reacts to different institutional incentives.

In this context, the following exploratory questions drive our empirical research. 
1. How can we define financial patents at the EPO and how many are issued, given the definition?

2. Which firms obtain financial patents? What are their characteristics - sector, size, age, listed vs. non listed, the size of their patent portfolio?

3. Do non-financial firms own a large share of these patents, as in the United States?

4. How do financial patents differ from other patents in their scope, citation of patent and non-patent literature, forward and backward citations, family size, and other characteristics?

5. Are European firms patenting financial innovations at the USPTO? How many also succeed at the EPO? That is, what is the pattern of equivalents?

Our paper contributes to the literature on the economics and management of patents in ways discussed below. First, while a growing body of evidence has focused on business method patents in the US system, the analysis of business methods patents in Europe is still in its infancy (e.g., Wagner, 2008). Moreover, to the best of our knowledge, this is the first study to focus on financial patents in the European context. Looking at financial patenting in particular is important because business methods encompass a highly heterogeneous set of technological and 'intellectual' innovations. When aggregating such different types of innovations one runs the risk of overlooking important peculiarities of innovation and patenting strategy in the financial sector.

Second, the patent literature distinguishes between patent quality and economic value or importance of patents. Patent quality refers to the statutory definition of a patentable invention novelty, non-obviousness and usefulness (or the production of a technical effect). Moreover, to be patentable an application must disclose sufficient information about the invention. The economic value of a patent depends on the expected profits accruing to its owner. Earlier studies have found that litigation and opposition are correlated with various indicators of patent value or importance (Harhoff et al., 2003; Lerner, 2006; Harhoff and Reitzig, 2004). Therefore, we estimate probit models for the probability of a decision by the EPO conditional on an application, a grant conditional on a decision, and an oppositions conditional on a grant that are similar to those in the literature, but focusing on our sample of financial patents. 
The paper is organized as follows. Section 2 describes the background literature and sets out some research hypotheses. Section 3 describes the data while Section 4 reports the results of the empirical analysis that compares financial patents to other patents and Section 5 presents an analysis of the outcomes at the EPO for financial patent applications. Section 6 concludes.

\section{Background and hypotheses}

To understand the quality and value of financial patents we need to clarify the peculiarities of financial innovations and to link these peculiarities to the economics of patenting. The main social function of the patent system is to increase private incentives for innovation by granting temporary monopoly power to inventors. In return for exclusivity, the patent owner is required to make the invention public rather than keeping it secret. In principle then the potential negative consequences for efficiency in the market for products due to the temporary monopoly are counterbalanced by the disclosure of information about the innovation.

Thus in theory the patent system yields several social benefits: providing greater incentives for $R \& D$ and diffusion of innovation, reducing the entry barriers faced by innovative startups with limited complementary assets, and increasing the efficiency in the market for intellectual property (Arora, Fosfuri, and Gambardella, 2001 and 2007). There are corresponding social costs in the form of the transactional and other costs patents may impose on those who wish to build on earlier inventions or combine several together in a new innovation. This problem is particularly important in technological areas characterized by cumulative, sequential innovations (Hall, 2003, among others). Moreover, patents favour an excessive fragmentation of intellectual property and increasing transaction costs due to enforcement and litigation (Heller and Eisenberg, 1998; Ziedonis, 2004). Finally, in industries characterized by strong network externalities and the requirements for standards, patents reinforce the monopoly power of the winners and may reduce future innovation.

The extension of patent coverage to business methods and software in the US system has raised concern that the imbalance between the benefits and costs of the patent system may be unfavourable in this technological area. "If it has been a policy experiment, could we determine today that it was successful? Probably not" (Hunt, 2008: 1). One may ask, however, whether the alleged imbalance between costs and benefits of patents is specific to this particular technology. 
To help to answer this question with reference to financial patents we have to note some important differences between innovation in financial services and manufacturing.

First, historically legal protection of financial innovations has been particularly weak relative to manufacturing. Trade secret has been the primary legal instrument to protect financial innovations but, unlike software, the use of trade secrets has become more difficult over time because the regulation of the financial sector has required a rising level of product and process transparency (Duffy and Squires, 2008). Moreover, financial institutions are subject to detailed scrutiny by public regulatory agencies and this may distract resources from innovation, especially for younger, small financial firms (Lerner, 2004). The weak appropriability regime and the use of the internet favour a rapid diffusion and imitation of financial innovations by competitors. This weakens the incentives for innovation especially in sectors like insurance where innovators bear the costs of developing a new product and obtaining the regulatory approvals but cannot prevent competitors from imitating its innovations very quickly (Hunt, 2008). In general, however, the lack of legal protection has not prevented the introduction of important product innovations (such as a multitude of financial instruments) and process innovations (such as trading platforms and pricing algorithms) in the financial industry, similar to the situation in the software industry prior to 1994/1995 (Torrisi 1998). The history of this industry clearly shows that 'the creation of new financial products and processes has been an ongoing part of economies for at least the past four centuries, if not longer.' (Tufano, 1989: 312).

Second, financial services are characterized by network externalities and strong demands for standardization. For instance, for financial exchanges and payment cards both attractiveness and efficiency (cost) depend on the number of users of the service. In other financial services, such as paper checks and automated clearinghouses, network externalities arise from interoperability, which is achieved by standard setting (e.g., standardized message formats). Standardization and compatibility between products typically give rise to strong market power for the owner of the standard. Patents can reinforce network effects and induce the accumulation of large patent portfolios for cross licensing purposes. In turn, this raises entry barriers and may hamper innovative entrants. Many financial innovations also require collaboration among financial institutions, for example, in syndications of innovative securities or standard setting for secure communication and transaction exchanges, implying a need to share access to patented inventions. In financial markets an innovator's success often relies on the existence of different 
versions of the innovation developed by competitors. These derivative, complementary innovations are important to "share the risk, increase market depth, liquidity, and price transparency" (Kumar and Turnbull, 2008: 2013). By patenting an innovation with a high potential for sequential innovations, a first-mover then can hamper market growth. Patents may hinder competitors from investing in co-specialized assets because of the hold-up risk (Kumar and Turnbull, 2008). By the same token, financial innovators who bear significant up-front costs to develop co-inventions compatible with an industry standard may be discouraged by the cost of licensing in the necessary patents. In the case of litigation for patent infringement with a patentholding company, the innovator finds it necessary to settle at relatively high cost because of their sunk R\&D costs and the costs of abandoning a standard that is already established. Litigation risk can therefore reduce investment in new standards (Hunt, 2008).

Finally, financial patents, like other business method patents, are often characterized by high uncertainty about enforceability. This is due to a number of factors. First is the absence of good non-patent prior art databases. Prior to the State Street v. Signature Financial decision in 1998 business method patent applications were very rare at the USPTO, so that there was little prior art on financial methods in the patent databases. In addition, most business method inventions have a practical nature and can be realized without much written documentation or are simply a known and used process transferred to the internet (Hunt, 2001; Wagner, 2008). Another reason for uncertainty arises from the use of ambiguous claims in patent applications which make it difficult to determine the boundaries of property rights for business methods and financial innovations. The importance of this problem for business method patents in general is emphasized by the fact that appeals over claims definition in this area are over six times more likely to occur compared with patents in general (Bessen and Meurer, 2008). Uncertainty over patent validity reduces the incentives to invest in innovation for both the patent holder and for the developers of competing inventions. These effects are strengthened in the presence of cumulative innovation like that in software and financial services. The inventors of subsequent, cumulative inventions may be discouraged by previous inventions that are covered by patents of uncertain validity - because they are obvious or have an indeterminate breadth.

This theoretical and empirical literature overall does not provide clear-cut evidence about the quality and economic importance of financial patents. However, various scholars have raised concerns about the lowering of barriers to business method and financial patents in the US 
institutional context. We wonder whether the evolution of the US patent system has produced any substantial effects on the application and granting of financial patents at the EPO, although the differences between the two systems remain significant. More precisely, our critical review of the literature on financial patents leads to a set of testable hypotheses that we present below.

The literature suggests that compared with other patents, financial patents are characterized by a higher level of uncertainty arising from the difficulty of establishing the novelty of financial inventions relative to prior art and the ambiguity of their claims. This uncertainty should affect both the application process and the post-grant litigation. An additional source of uncertainty for financial patent applications filed at the EPO arises from art. 52 of the EPC which excludes business methods and software 'as such' from patentable subject matters. Examination of financial patents at the EPO then is likely to be particularly complex since examiners have to distinguish pure business methods, which are not patentable, from patentable financial inventions. We expect then the likelihood that we observe a larger grant lag or a rejection is larger for a financial patent than for another patent with identical quality or value characteristics, such as the number of citations received by other patents. These considerations lead to the following two hypotheses:

Hypothesis 1a. Ceteris paribus, financial patent applications should have longer decision lags than patent applications in other technological areas.

Hypothesis $1 b$. Ceteris paribus, financial patent applications should have a lower probability of grant than patent applications in other technological areas.

The literature also suggests that the extension of patent coverage to subject matter where patents are difficult to define and to enforce gives rise to large litigation costs. Previous empirical evidence based on US patents suggests that financial patents, like other business method patents, are a case in point (Lerner, 2006). As mentioned before, the opposition system at the EPO is an important instrument for first-instance challenges to the validity of granted patents. As Harhoff and Reitzig (2004) have noted, this instrument offers a 'fast and inexpensive resolution of legal disputes' (p. 445). ${ }^{3}$ Working on patents data in biotech and pharmaceuticals, Harhoff and Reitzig have found that opposition rates are particularly high in new technical areas, such as special areas of biotechnology (p. 457). Their results are in line with the predictions of the theory of

\footnotetext{
${ }^{3}$ Harhoff and Reitzig (2004) estimate that an opposition case typically costs each party between 15 and 25 thousand euros - only a very small part of which is accounted for by opposition fees (p. 450).
} 
legal disputes and settlement (see Cooter and Rubinfeld, 1989 for a survey). Looking at the oppositions filed to the EPO we ask whether the probability that a financial patent is opposed is larger than the probability for non-financial patents of similar quality or value. The uncertainty and claim ambiguity that characterize business method patents in general and the limitations to patentability of business methods "as such" in Europe suggest that financial patents that have been granted should be litigated more often than other patents. More precisely, we test the following hypothesis:

Hypothesis 2. Ceteris paribus, the probability that a financial patent is opposed is greater than that for patents in other technological areas.

Thus far we have focused on the differences between financial patents and other patents, controlling for the quality or importance of patents. One may also ask, however, whether and how quality affects the examination outcome and the post-grant opposition probability in the case of financial patents.

Various studies have demonstrated that the outcome of the examination process (grant, refusal to issue, or withdrawal by the applicant) is only an imperfect measure of the quality or economic importance of a patent (e.g., Lanjouw and Schankerman, 2004b; Hall, Jaffe and Trajtenberg, 2005). And, as discussed before, several scholars have cast doubt on the quality of financial patents granted by the USPTO. ${ }^{4}$ To better understand financial patenting at the EPO we need to look at more precise indicators of quality and importance of patents. Earlier studies have proposed several measures such as the number of inventors, the number of backward and forward citations, the number of claims and family size or the number of patent systems worldwide where patent protection is sought for the same invention. The empirical evidence shows that all these indicators, to various degrees, are associated with the importance or economic value of patents (e.g., Harhoff et al. 1999; Hall, Jaffe and Trajtenberg, 2005; Lerner, 1994). Other studies have also found that a linear combination of these indicators can serve as a

\footnotetext{
${ }^{4}$ The term patent quality does not have a universally accepted definition, but we use it to mean an application that is more likely to satisfy the novelty, non-obviousness, and subject matter restrictions, and whose validity and ability to withstand subsequent challenges is therefore more certain (see Hall 2003 for a discussion).
} 
proxy for the economic value of patents (Lanjouw and Schankerman, 2004b; Hall, Thoma and Torrisi, 2007; Gambardella, Harhoff and Verspagen, 2008).

Finding measures of patent "quality" is somewhat more difficult. For example, references to prior patent art (backward citations) can be a somewhat ambiguous such measure. Some scholars have suggested that large numbers of citations to others reveal that a particular invention is likely to be more derivative in nature and, therefore, of limited importance (Lanjouw and Schankerman 2004a). However, a large number of backward citations may also indicate a novel combination of existing ideas. This is probably the reason why Harhoff et al. (1999) have found that backward citations are positively correlated with patent value. A more precise indicator is provided by the number of X-type and Y-type citations that are references to prior art potentially challenging the novelty claims of the patent. ${ }^{5}$

The lack of documented prior art and the uncertainty surrounding financial patents may make it difficult for EPO examiners to identify patents which provide a significant, non-obvious contribution to prior art. This suggests the possibility that financial patents may be granted that are of low quality (lack novelty or are obvious). Such patents are also likely to be of low value, social or economic. We expect that, despite the difficulties mentioned before, the traditional severity of the EPO examination system (see, e.g., Quillen, Webster, and Eichmann, 2002) and the EPC restrictions on business method patentability help patent examiners to distinguish important patents (e.g., patents that will receive many citations), from patents that provide a modest contribution to prior art (e.g., the patent cites prior art potentially challenging its novelty claims). ${ }^{6}$ Moreover, we expect that the number of claims, a proxy for patent complexity (Harhoff and Reitzig, 2004), will slow the patent office decision and reduce the likelihood of grant. These considerations lead to the following hypothesis:

Hypothesis 3. Ceteris paribus, financial patents are less likely to be granted if they have fewer citations received, contain a large number of claims, or have several overlapping claims with earlier patents (many XY-type backward citations).

\footnotetext{
${ }^{5}$ It is important to note that at the EPO, references to the patent and non-patent literature (scientific publications) are assigned by the examiner, not by the applicant. X-type citations refer to patents containing claims that overlap with claims in the patent under examination. Y-type citations refer to patent applications containing claims that combined with other claims overlap with claims in the patent examined.

${ }^{6}$ That is, the patent has backward citations classified as X-type or Y-type by the EPO.
} 
Our final hypothesis concerns the probability that a financial patent will be challenged by an opposer after it is issued. The theory of legal disputes suggests that patent oppositions are likely to occur under conditions of high uncertainty and imperfect information. This is one reason why we expect that the complexity and problematic enforceability of financial patents relative to other patents make them more likely to be opposed. ${ }^{7}$ However, the theory of legal disputes and their resolutions also argues that valuable patents will be litigated more frequently because there is more at stake (Cooter and Rubinfeld, 1989 for a survey).

Empirical studies on US patents (Lanjouw and Schankerman, 2001, 2004a,b), US financial patents (Lerner, 2006) and EPO patents in biotech and pharmaceuticals (Harhoff and Reitzig, 2004) have found evidence on the association between the value of patents and litigation. All of these studies found that citations received (a proxy for value) are positively associated with litigation. However the findings using backward citations (a proxy for the quality of disclosure or for the crowdedness of the technological space) vary considerably. Lanjouw and Schankerman (2004a) finds that backward citations per claim are negatively associated with litigation probability, whereas Lanjouw and Schankerman (2004b) finds that other value measures are positively correlated with litigation. However, Lerner (2006) found that backward citations in financial patents are positively associated with litigation. Harhoff and Reitzig (2004) provide a potential resolution of this conundrum using EPO patents, where it is possible to distinguish among the types of citations made. They found that it is the citations to patent literature that potentially challenge the novelty claims of the patent (X-type citations) and not the other backward citations which predict opposition. This finding suggests that more incremental (less valuable) patents or patents with a technologically close competitor are more likely to be opposed

The probability of litigation in the US has also been found to increase with the number of claims both for all patents (Lanjouw and Schankerman, 2004a) and for financial patents (Lerner, 2006). The economic interpretation of claims is quite controversial. It is unclear whether they are a measure of patent complexity (Harhoff and Reitzig, 2004) or a proxy for potential profitability

\footnotetext{
${ }^{7}$ Later in the paper we do find that the opposition probability for financial patents is significantly higher than that for other patents ( 9 per cent versus 6.5 per cent, without correcting for the overall decline in opposition probability during the period; the correction would increase the difference slightly).
} 
(Lanjouw and Schankerman, 2004b), or, most likely, a combination of both. In any case, we expect the number of claims to be related to opposition.

Finally, the potential economic value of an invention will determine the applicant's willingness to file for a patent in multiple jurisdictions, because doing so involves substantial expenditure (not just the patent office fees, but also the costs of attorneys, translation fees, etc.). For this reason, and beginning with the work of Putnam (1996), the number of patent applications that share the same priority date as the patent in question (the family size) is a frequently used proxy for patent value (Harhoff, Scherer and Vopel, 2003; Harhoff and Reitzig, 2004).

These considerations lead to the following two hypotheses:

Hypothesis 4a. Ceteris paribus, more valuable financial patents (that is, those with more forward citations or a larger family size) are more likely to be opposed.

Hypothesis $4 b$. Ceteris paribus, more controversial financial patents (those with more claims or more XY-type backward citations) are more likely to be opposed.

The above concludes the presentation of our hypotheses. In order to test them, we need to identify financial patent applications at the EPO, and a corresponding sample of non-financial patents for comparison. This task is described in the next section of the paper.

\section{Data}

\subsection{Defining Financial Patents}

As in the case of software or business method patents (Hall and MacGarvie 2007; Hall, Thoma and Torrisi, 2007; Hall 2003; Bakels et al. 2008), identifying financial patents precisely (with no Type I or II error) is difficult. To some extent, the difficulty lies in the fact that we do not have a precise definition of what we mean by a financial patent, although we are fairly sure we can tell one when we see it. The most important IPCs in which the patents we identify as financial may be found are described as "complete banking systems," "mechanisms activated by other than coins .....to actuate vending, etc ....by credit card," "office automation or reservations," "finance, e.g., banking, etc.", "payment schemes," but also by more generic terms such as "Digital computing or data processing equipment." Many, but not all, of these patents are associated with payment systems, cash machines, or vending machines, but some are more 
related to innovation in financial instruments. As can be seen in Appendix A, we found it essential to use keywords to restrict any set of patents identified using simply technology classes.

Duffy and Squires (2008) have examined a sample of recently granted USPTO patents classified in the USPC class $705 / 35 .^{8}$ They found that only a few of these patents are about sophisticated trading mechanisms, valuation metrics or innovative financial products. The innovations described are all relevant to the financial industry but they are not pure financial innovations. Moreover, among the patents closely connected with finance, only a few disclosed 'cutting edge financial engineering ... cognizable as a significant development in financial theory' (Duffy and Squires, 2008: 26). Their evidence suggests that it may be important to develop robust definitions to identify financial patents in the US and European patent offices. We begin such an exploration here, but are aware that there is room for further work in this area.

Our investigation explores three different methods of choosing such patents: A) EPO equivalents of USPTO patents in certain finance-related class/subclass combinations; $\left.{ }^{9} \mathrm{~B}\right) \mathrm{EPO}$ patents in a set of IPC/ECLA finance-related classifications; and C) EPO patents in technology classes where "pure play" financial firms patent. Financial patents at the EPO seem to be scattered among a large number of classes and there was relatively little overlap across the three sets. Therefore we used the union of the three sets as our definition, but at the same time we restricted the sample to those with one of eight specific keywords in the title or abstract: transaction, financial, credit, payment, money, debit card, portfolio, and wallet. After dropping a few observations due to missing applicant information, this yielded a sample of 3,298 patents with priority year between 1978 and 2005, about 4 per cent of the initial 87,719 patents in the union of sets A, B, and C. The details of the patent selection algorithm are given in the appendix A.

The analysis in the next section of the paper is based on a comparison of financial patents with all other patents. To form the comparison group of all patents we took a random one per cent sample of the EPO database (excluding financial patents), obtaining 18,523 patents. The

${ }^{8}$ Class 705 is "Data processing: financial, business practice, management, or cost/price determination" and subclass 35 is "Finance (e.g., banking, investment or credit)".

${ }^{9}$ Although this clearly biases the selection toward firms operating in the United States, because we use the union of this criterion with the other two (Sets B and C), we expect the bias to be small. 
relatively large size of the sample ensured that the sampling variability of the comparison group was rather small.

\subsection{Variable definitions}

Outcome of the examination process - Patent applications are subject to an examination process that can lead to the following outcomes: refusal of the application, withdrawal of the application or a patent grant. Knowing whether a decision has been reached for a patent application provides useful information about the complexity and uncertainty of the examination process. The literature often refers to the outcomes of patent applications at the EPO (refusal, grant, and withdrawal) as indicators of patent quality or eligibility of a financial invention for patenting. In addition, applicant practice is often to withdraw an application when it becomes clear that it will be rejected, so the distinction between refusal and withdrawal is blurred (Lazaridis and van Pottelsberghe, 2007). We generated two dummy variables if a decision has been taken and if a patent has been granted conditional on decision, respectively.

Opposition - Oppositions can be filed at the EPO within nine months from the granting date and it is quite inexpensive compared to litigation in the courts. We constructed a binary variable which takes the value 1 if a patent has been opposed.

\section{Independent variables describing the prior art base}

By prior art base, we mean the knowledge on which the invention described in the patent relies, as indicated by the various types of citation to earlier patents and non-patent literature. The variables analyzed are listed and described more precisely below.

- Total cites to the non-patent literature in the patent document, which has been shown to be related to the closeness to "science" and patent value (e.g., Meyer, 1999).

- Total backward cites (to other patents) in the patent document. Contrasting evidence exists regarding backward citations. On the one hand a higher number of citations may indicate that the patent relies on a broader knowledge base and hence is more important; on the other hand, it may suggest that the patent is more derivative in its nature or that it is in a crowded technological area and so has narrow breadth. 
- XY backward cites in the patent document. At the EPO the task of the examiner consists not only in the identification of patent documents that can be considered prior art for a given patent application, but also in the classification of the prior art patent(s) by degree of importance to that patent application. The categories $\mathrm{X}$ and $\mathrm{Y}$ signal that at least one claim of the patent application overlaps completely or partially with at least one claim of the prior art patent(s).

- XY backward cites per inventor.

- The average age of the backward citations (citation lags) in months, an indicator of the rate of technical change in the area of the invention.

Independent variables related to patent "value" or "importance"

- Family size (the number of patents internationally that share the same priority). Economic value is related to the willingness of the patentee to pay the various fees involved in taking out a patent on the same invention in multiple jurisdictions.

- Number of designated states for the patent at the EPO (the number of EPC nation-states in which the applicant can request coverage when the patent issues).

- PCT route. This is a dummy that signals whether the applicant has filed an international application to extend patent protection beyond the EPC member states.

- Number of technology classes (IPCs) in which the patent was classified by the EPO; this is often considered a measure of breadth or scope. The number of technological classes has been shown to be an indicator of technological "quality" similar to the number of citations by Lerner (1994). However, as noted by Guellec and Pottelsberghe de la Potterie (2000), this variable may be also a measure of ambiguity reflecting the difficulty of the examiner in locating the invention in the technological space.

- The number of forward cites received by the patent or its equivalents during the first three years (from PATSTAT). This is a measure of the technological importance of the innovation.

- A continuation dummy if the patent had at least one divisional at the EPO that shared the same priority; because divisionals occur when a patent describes more than one invention, this may also be an indicator of a broader or more valuable patent. 
- A composite value index based on family size, forward citations and the number of IPC classes at the 8-digit level, described in Hall, Thoma and Torrisi (2007). They show that this composite index is associated with firm market value after controlling for several other variables in a sample representing about 1000 largest R\&D doers among European publicly listed firms. ${ }^{10}$

\section{Independent variables describing the patent owner}

Variables accounting for the characteristics of the patent owner have been used in the analysis of opposition. The following set of variables has been taken into account.

- Log stock of EP patents of the patentee (depreciated at $15 \%$ annual rate) - a proxy for the experience of the patentee.

- Log stock of forward cites per patent of the patentee. This variable is obtained by dividing EP patent citations received (first three years only, depreciated at $15 \%$ annual rate) by the stock of patents depreciated at same annual rate - a measure of the average value of the patentee's inventions.

- Log stock of XY backward citations by EP patents of the patentee (depreciated at $15 \%$ annual rate) - a proxy for the absence of inventive step in prior inventions, or for operating in a crowded technological field.

- For firm size we used three categories defined by the European Network for SME research (ENSR) of the EC SME observatory (see Table 1).

- Age of the patentee (dummies for firms that were founded between 1981 and 1995, and after 1995, with those founded prior to 1981 the left-out category). Preliminary explorations showed including a more detailed set of dummies lowered precision but did not change the results.

- Sector of the patentee (dummies for the 6 leading sectors plus the remainder in the leftout category).

\footnotetext{
${ }^{10}$ The index draws on a methodology first developed by Lanjouw and Schankerman (2004b).
} 
- Country of the patentee ( 5 dummies for US, Japan, Germany, France, and the UK, with the remaining countries as the left-out category).

\section{Trends and descriptive statistics}

The trends of aggregate and financial methods patenting at the USPTO and EPO are displayed in Figures 1 and 2 respectively. Figure 1 shows aggregate EPO grants and applications and USPTO patent grants (all by priority year), while Figure 2 shows the trends in financial methods patenting at the two agencies. ${ }^{11}$ Note that prior to about 1991 or 1992 the trends in all patents and financial patents are very similar. The growth of EP financial patenting follows the growth of US financial patents closely, although the latter set accelerates more rapidly in 1999 and 2000 and decelerates more quickly after that.

Relative to overall patenting activity, financial patents show a very rapid growth in the years 1994 and 1995, which are the years of the main software patentability decisions in the U.S., and also the years during which use of the internet took off in that country. Both in the EPO and USPTO, by 2006 there were approximately three times as many patents as in 1991 overall, and six times as many financial patents. Even though the EPO subject matter restrictions in the software and business method area are narrower than in the United States, the growth of financial patents at the EPO doubtless reflects the impact of the State Street decision in the United States in 1998 and the changing attitudes toward patenting among business services and financial firms which that decision engendered.

\section{[Figure 1 about here]}

\section{[Figure 2 about here]}

Note also that at the end of the period (after about 2001), there is a substantial falling off in all types of patents, due to the lag between priority year and publication (at the EPO) or grant (at the USPTO). Nevertheless, there also appears to be real decline in the growth rate of patent

\footnotetext{
${ }^{11}$ The precise definitions of the series shown are the following: All EP patents - patent grants and patent applications to the EPO; all US patents - patent grants by the USPTO; EP financial patents - the union of sets A, B, and C; EP business method patents - equivalents of US business method patents; US financial patents - the union of the sets defined by Hall (2007) and Lerner (2006); US business methods patents - all USPTO patents having at least one US patent class equal to 705 or 902 but excluding financial patents. All series are shown by priority year or application year if the priority year is not available.
} 
applications at both offices which is not accounted for by the grant lag. This trend may be only partially due to a change in the application strategy after the Business Patent Initiative was announced by the USPTO in year 2000. Since the aim of this initiative was to raise the examination standards for patent applications in class 705, applicants may have tried to avoid filing applications in this class by a careful choice of wording. However, this does not explain the decline in the growth rate of total patent applications.

To illustrate the characteristics of the patentees who take out financial patents at the EPO, we focus on the 90 per cent that are taken out by businesses. ${ }^{12} \mathrm{We}$ look at the country of origin, the business sector, and the size of firm. In our regression analysis we ask how these variables are related to outcomes at the EPO. To save space, we relegate several tables to Appendix B and summarize their results here.

Table B.1 shows that a large share of EP financial patents are filed by US applicants (49\% versus 34\% for European patentees and 13\% for Japanese patentees), with the surge from the US beginning some 4-5 years earlier than that from the EU. Prior to 2000, applicants from the US accounted for over half (57 per cent) of the financial patents at the EPO, and after 2000, only 45 per cent. The overall decline in patenting and the shifting shares probably reflects two things: the dotcom bust in 2001, which had a bigger impact in the United States, and the diffusion of patenting activity in this area to European firms.

This distribution however remains clearly more asymmetric in favor of US applicants than overall patenting activity or even patenting in Information and Communication Technologies (ICT) at the EPO (see Patent Compendium, OECD 2008). The persistent large share of US assignees probably reflects the differences in the treatment of financial and business method patents between the US patent system and other systems. Another plausible explanation is the high intensity of financial innovations in the US economy vis-à-vis other economies. For comparison, we also show in Table B.2 the distribution of assignee country for financial patents

\footnotetext{
${ }^{12}$ There are a total of 3,298 patents in our sample. Of these, 169 have more than one applicant (in a few cases more than two). In the next section we include all the patents, but only once each, so the total number of observations is 3,298 . In this section we focus on those applicants that were in the business sector, excluding individuals and government applicants, for a total number of observations equal to 2,998, corresponding to 2,934 patent documents, of which 52 have more than one applicant. Note that the 11 observations where the sector of the applicant could not be identified were also removed from this sample.
} 
filed at the USPTO, which is even more skewed towards to U.S. It also shows that most of the patenting at this office is accounted for by applicants in the US, Japan and the EU. The share of financial patents held by US patentees rose during the 1990s and then fell somewhat after that as European applicants increased their share. About two-thirds of European-owned financial patents come from the largest three countries, the UK, Germany, and France.

Table 1 in the text depicts the distribution of financial patents by the main activity of the patentee. We used different sources to identify the main activity of the applicant, successfully obtaining this information for almost all (99.7\%) of the financial patents owned by businesses. ${ }^{13}$ There is a very high concentration of patents in a few sectors: in particular, only six sectors account for about $70 \%$ of the financial patents overall and $82 \%$ from the business sector, with four of them being services - computer services including software, financial services, telecommunications, and other business services - and the remaining computer-related hardware. This is in line with the concentration of software patents reported by Hall, Thoma and Torrisi (2007).

The concentration of patents in these six sectors is higher for US applicants than for EU applicants. Moreover, the two leading sectors in Europe differ significantly from the ones in the US: in the former case telecommunication firms, computer-related services, and communications equipment are responsible for $52 \%$ of the business sector financial patents, whereas in the US, firms in the computer hardware, computer services, and financial sectors hold $73 \%$ of them. In Europe, firms in the financial sector account for only $11 \%$ of business sector financial patents. These differences in distribution doubtless reflect the strength of the telecommunications sector relative to the software and financial sectors in Europe vis-à-vis the US.

\section{[Table 1 about here]}

Prior to 1994/1995 there was little patenting in this area. After the U. S. Court of Appeals of the Federal Circuit (the CAFC) removed the restriction on patentability of software as such in 1995 and then again after the State Street decision in 1998, there were spikes in financial patent applications, the first due to computer hardware, telecommunications, and other business sectors,

${ }^{13}$ In particular, we used Amadeus for European firms, Hoover's and Who Own Whom for US companies, Jade for Japanese firms, and the company's websites for any firms not found on one of these sites. 
and the second mostly from computer hardware and finance and insurance. Between 1993 and 1998 average annual patenting in this technology jumped from 20 patents per year to 100 patents per year. However, in the period after 2000 the growth appears to have moderated somewhat and a higher share come from software and finance/insurance firms. The breakdown by sector and firm age shown in Table B.3 in the appendix demonstrates that the service firms that hold financial patents tend to be much younger than the manufacturing firms. Thus even in Europe, there appears to be a shift in attitudes toward patenting among the newer entrants in business service sectors.

Table B.4 in Appendix B looks at the size of the firms taking out financial patents. ${ }^{14}$ The majority of financial patents are obtained by large patentees: however their role decreased somewhat after 1999 in favor of the small-sized firms. Moreover, the small patentees are concentrated in a few sectors. Indeed, about $78 \%$ of the financial patents held by small sized firms are held by firms in three service sectors - software, financial and other business services whereas these sectors account for less than half (40\%) of patents filed by large firms. It is interesting to note that SMEs account for about $24 \%$ of financial patenting at the EPO.

The small patentees operating in the service sectors are also new firms: firms born after year 1995 account for over $60 \%$ of the financial patents by small patentees, whereas their role in the overall patenting is minimal (Table B.5). In contrast, the great majority of patents held by large firms are held by firms that were founded prior to 1970, as one might expect. Typically the emergence of smaller firms active in financial patenting is associated with the advent of the socalled Internet economy. Their business models often rely on licensing transactions and financial models embodied in a software application that uses non-exclusive technology contracts. This can be seen in Table B.3, where firms founded after 1990 that take out financial patents are more likely to be found in the service sector. In contrast, a large share of the communication equipment and telecommunications firms that have financial patents were born during the 19811990 period with the advent of wireless and cell telephony.

\footnotetext{
${ }^{14}$ For firm size, we used three categories that are compatible with the definition given by the European Network for SME research (ENSR) of the EC SME observatory: i) small, having 1-49 employees; ii) medium, having 50-249 employees; iii) large, having more than 249 employees.
} 
A higher propensity to patent is consistent with the active participation in technology markets, where IP protection of the goods being traded is important. Ongoing research has not yet reached a definitive conclusion on the sustainability in the long run of such business strategy. However, the development of specialized technology providers in the financial area could be considered a quintessential example of the vertical disintegration that takes place when ownership of innovation assets becomes available (Arora et al. 2007; Thoma 2008).

Table 2 shows the approximately 50 largest patentees in our sample; almost all of them are large and old firms. Nevertheless, there are a number of newer entrants among the next 50 such as Bitwallet (electronic money service provider in Japan), Orbis Patents (patent holding company in Ireland), Trintech (transaction software provider in Ireland) and Contentguard (DRM technology in the US).

\section{[Table 2 about here]}

\subsection{Comparing financial patents to other patents}

In this section the characteristics of financial patents are compared with all patents at the $\mathrm{EPO}$, in order to explore potential differences regarding the prior art base and to get some idea of the economic value or importance of this kind of patenting.

Because most of the variables we consider will vary systematically over time, and because financial patents are disproportionately represented in the later years, we normalized each of the variables by its overall year mean before performing tests for differences between the two samples. Table 3 shows the results of our analysis: it contains some simple statistics on the unadjusted data for the two sets of patents, and the results of t-tests comparing financial patents with all other patents. These tests were conducted using the priority year normalized variables. We used a conventional two-sample t-test for differences in the mean, allowing the two samples to have different variances.

The upper panel of Table 3 reports some measures of the prior art base for the two sets of patents. Financial patents cite slightly newer prior art than patents as a whole (average age about 60 months versus 64 months), and the difference is significant. They also have significantly fewer backward citations (whether XY or otherwise) and citations to the non-patent literature. 
They have the same number of inventors on average, suggesting that the resources invested in them are roughly comparable with resources invested in other patents.

\section{[Table 3 about here]}

The middle panel of Table 3 shows some indicators that are commonly associated with patent value: the number of claims, the number of technology classes (IPCs) in which the patent is classified, the number of patents in the rest of the world with the same priority date (the number of equivalents), whether there are one or more divisionals (continuation) at the EPO associated with the patent, the number of countries in which coverage was requested at the EPO, the number of citations received by the patent in the first three years after grant, and the HTT composite index based on family size, IPC classes, and forward citations. ${ }^{15}$

On a number of these value measures, financial patents differ substantially from other patents. Financial patents have similar equivalents (family size), divisionals, and number of designated states. They have more claims, are more likely to be cited, and are more likely to reach the EPO via the PCT route. The composite value index of family size, citations, and the number of IPCs is higher on average than that for other patents, once we adjust for differences across priority years. Note that the higher rate at which financial patents are cited may indicate higher social value as well as higher private value, because it implies greater "spillovers" of knowledge to future inventors than yielded by the typical patent. We should notice that small population of financial patents at the EPO reduces the likelihood of citations between financial patents. The high number of citations received then suggests that these patents are mostly cited by patents from different technological classes. The larger number of citations received by financial patents is in line with the large number of forward citations of business method patents reported by Wagner (2008).

Financial patents are classified into significantly fewer IPC classes than all patents, which is a bit surprising, since business methods and software inventions are excluded from the patentability 'as such' in EPO according to art. 52 of the statute, and hence there is a lack in EPO of a clear technological classification for this type of patenting; nevertheless, this fact seems to

\footnotetext{
${ }^{15}$ The HTT index relies on the factor analysis for the construction of a synthetic indicator of patent value. For further information see Hall, Thoma, and Torrisi (2007).
} 
lead the examiner to place the patent in fewer rather than more classes. The suggestion is that these patents have less breadth of applicability.

Finally, financial patents have a significantly larger number of claims compared with other patents, which suggests a greater complexity as compared to other patents.

\subsection{Outcomes at the EPO}

Most of the analysis in this paper is based on the published patent documents on the EPO website. These documents are patent applications that may ultimately be rejected, withdrawn, or granted by the EPO. One indicator of the "quality" or eligibility of these financial inventions for patenting is their experience in the EPO examining and granting process (Harhoff and Wagner, 2005). In the bottom panel of Table 3 , we show some simple statistics on this question for our two groups of patents. The first question is whether a decision has yet been rendered by the EPO. For three quarters of all patents, the answer is yes, but for financial patents there are somewhat fewer decisions, partly because their applications are on average newer. When we adjust for this fact, these applications are just as likely to have received a decision.

The possible outcomes for an application are that it is granted, that the EPO refuses it, or that the applicant withdraws it after negotiation with the EPO. The decision to withdraw a patent application can be considered equivalent to having received a rejection. In this way, the patentee can preempt a potential rejection decision of the examiner after the dispatch of the results of the examination process (Lazaridis and van Pottelsberghe, 2007).

Table 3 shows clearly that conditional on a decision having been reached, financial patents are far less likely to be granted than other patents, indicating that the EPO is finding these applications unpatentable more often than other patents, which is probably related to the subject matter restriction of art. 52. Correspondingly, they are more likely to be either refused or withdrawn. If they are granted, the process takes longer than other patents (as suggested earlier). Once again, after adjusting for the differences in time profiles, these differences are not statistically significant. Note that granting rates for business methods patents overall are significantly larger than for overall patents (Wagner, 2008).

The final step in the EPO process before the patent becomes a set of national patent rights that can be enforced in national courts is the 9 month post-grant window during which any third 
party may file an opposition against the patent showing that it should not have been granted. The overall rate at the EPO for opposition during the 1978-2005 period is about 6.5 per cent, but financial patents have been opposed 9 per cent of the time, which is significantly higher.

The aggregate numbers mask some interesting changes that have occurred over time. In Figures 3 and 4 we show the evolution of the grant rates and opposition rates for the two groups of patents at the EPO between 1978 and 2002. ${ }^{16}$ Three periods can be discerned: In the first, roughly 1978-1985, financial patents were much less likely to be granted than the other patents, but also less likely to face opposition, once granted. Between 1986 and 1993, grant rates for all types of patents were roughly comparable, while financial patents were about 3 times as likely to be opposed once granted. Then beginning around 1994, the grant rate for financial patents fell precipitously along with the opposition rates. Financial patents now face the same rate of opposition as other patents. The conclusion is that greater scrutiny at the EPO has led to an decrease in the issuance of controversial patents; the question remains whether this has also eliminated more valuable patents.

\section{[Figures 3 and 4 about here]}

\section{The determinants of EPO outcomes for financial patents}

In order to test hypotheses 1 and 2 and to explore the determinants of a successful application at the EPO, we estimated a series of probit equations for the probability of a decision conditional on an application, a grant conditional on a decision, and opposition conditional on a grant. Controlling for average differences across time, whether a decision has yet been reached can be an indicator of the quality of the original application and of the speed with which the patentee pursues the application. Given a decision, whether or not the patent is granted is first and foremost an indicator of invention quality, and also of whether the invention is viewed as satisfying the subject matter restrictions. Finally, opposition has been shown repeatedly to be an indicator of the economic value and importance of the patented invention (Harhoff et al. 2003, Harhoff and Reitzig 2004).

\footnotetext{
${ }^{16}$ These periods are based on priority years, so there are too few granted patents in 2003-2005 to see much in the way of opposition. We therefore ended the detailed analysis at 2002.
} 
The explanatory variables for these equations are a selection from the variables described previously, plus a dummy for financial patents. That is, in order to test hypotheses $1 \mathrm{a}, 1 \mathrm{~b}$, and 2 , we ask whether financial are more or less likely to receive a decision, be granted, and be opposed given their prior art and value characteristics and priority year. All variables except the continuation (divisional) and PCT dummies are in logarithms to facilitate interpretation. We also included a complete set of priority year dummies in the regressions.

The results are shown in Table 4. As expected, the sample sizes get successively smaller, from decision conditional on application, grant conditional on decision, and opposition conditional on grant. In the latter case we removed a few observations for 2004 and 2005, since there were two few grants corresponding to those priority years for opposition to be observed. The three groups of variables (priority year dummies, prior art indicators, and value indicators) were always highly jointly significant using a Wald-type test. In general, the results for these variables agree with those in prior work: backward references increase the probability of receiving a timely decision, but not if they are of the XY type, whereas backward references to patents increase the probability of a grant, with XY type backward citations reducing the probability substantially and increasing the probability of opposition, once the patent is granted.

Almost all the value indicators reduce the probability of receiving a decision and of having that decision to grant the patent, while increasing the probability of opposition significantly, as expected. The one important exception is the size of the patent family: this has no impact on the speed with which a decision is reached, but a substantial impact on the probability of a grant (an increase of 0.37 from a doubling of the family size). This may reflect the fact that the inventions associated with patents that have been applied for in many jurisdictions are more important (have greater novelty) and are more likely to have satisfied the subject matter restrictions. ${ }^{17}$

Financial patents are strikingly different from other patents with the same characteristics, being less likely to receive a decision, less likely to be granted, and slightly more likely to be opposed. Thus hypotheses $1 \mathrm{a}$ and $1 \mathrm{~b}$, which state that financial patents will have longer decision

\footnotetext{
${ }^{17}$ The PCT dummy and family size are correlated because using the PCT route implies a desire to take out the patent in more than one country. Although the PCT coefficient is significantly negative, which will weaken the impact of family size, when it is removed, the coefficient falls only slightly (to 0.34 ).
} 
lags and are less likely to be granted, fail to be rejected. The evidence in favor of hypothesis 2 , that financial patents are more likely to be opposed, c. p., is somewhat weaker, but that may be due to the relatively small sample of oppositions (53 for the financial patents).

All of this suggests that these patents are of lower quality technologically than the others and simultaneously more valuable or at least more controversial, other things equal. Because of the higher opposition rate faced by financial patents, which concords with the value indicators shown in Table 3, we can conclude that these patents, once granted, are expected to be of higher economic value than other patents. As we argued earlier, the outcomes of financial patents relative to other patents reflect a more stringent scrutiny of this category of patent applications by the EPO. The longer decision lag, however, may also depend on the complexity and uncertainty surrounding these patents compared to others. Finally, the lack of documented prior art may contribute to the difficulty of obtaining a patent grant for financial innovations.

\section{[Table 4 about here]}

Hypotheses 3 and 4 concern the variation across financial patents and we test these hypotheses in Table 5, where we repeat the analysis of Table 4 but restrict it to the 90 per cent of the financial patents that are held by firms in order to include the influence of firm characteristics on outcomes at the EPO. The sample consists of 2,998 patent applications corresponding to 1021 patentees that have priority year 2005 or earlier. Almost three quarters of the patentees (998 observations) have applied for only one financial patent at the EPO, while one (IBM) has applied for more than 100 .

There are two sets of explanatory variables included in these equations: the characteristics of the applicant firm, and the characteristics of the patent application itself. We also include a reduced set of priority year dummies. Three probit regressions are shown: 1) predicting the 1,718 decisions for the 2,998 applications that have priority year 2005 and a decision prior to October 2008; 2) predicting the 618 grants that emerge from those decisions; and 3) predicting the 53 oppositions filed against the 553 grants that have priority year 2000 or 
earlier. ${ }^{18}$ All standard errors in Table 5 have been clustered by patent owner, although this makes relatively little difference to their estimates. ${ }^{19}$

Turning first to the probability of obtaining a decision on patentability at the EPO, controlling for patent characteristics and priority year the most important predictor among the owner characteristics are whether the firm is Japanese, which appears to delay the decision considerably; this may reflect delays associated with distance and translation. German firms seem to experience a correspondingly faster decision process. With the exception of mediumsize firms, who receive a somewhat quicker decision, the firm's size, sector, and past patenting history do not seem to matter much. The stock of patents and XY backward citations have a quite limited impact on the likelihood of obtaining a decision. What does matter are the characteristics of the patent itself: forward and backward cites raise the probability of a decision, while inventors and the number of designated states lower it. ${ }^{20}$ This suggests that more valuable financial patents that have more resources behind them take longer to issue or be rejected, other things equal. This may reflect the applicant's willingness to extend the process at the EPO when more is at stake.

Once a decision has been reached, however, the probability of grant is more affected by the characteristics of the patent owner. Although size of firm does not matter in the presence of the size of the firm's patent portfolio, sector and country do matter. Patenting experience counts for a great deal: a doubling of the firm's patent portfolio is associated with a 16 per cent increment in the probability that a financial patent is granted. Firms in computing hardware or software experience a higher probability of receiving a financial patent grant than firms in other business sectors, while firms in finance and insurance have a lower probability. This may reflect inexperience on the part of these firms, also when compared with software firms, but it is more likely to be due to the nature of their patent applications, which may fail the subject matter test more often. Patent application in the hardware sectors are more likely to be for the kinds of

${ }^{18}$ There are no oppositions for the grants of financial patents with priority year after 2000 , so we excluded those years from the analysis in the last column (53 observations).

${ }^{19}$ However, doing things this way has the advantage of making both our estimates and standard errors consistent even if there are random firm effects. Given the large number of firms (over 1000) with only a single patent, using a fixed effect estimator is not very attractive as it would drop too many observations.

${ }^{20}$ Since family size and the number of designated countries are correlated, in unreported regressions we tried with only one of these variables and the results do not change substantially. 
software-hardware combinations that are viewed as patentable subject matter by the EPO. ${ }^{21} \mathrm{US}$ and Japanese patent owners (who presumably are more likely to have patent applications outside the art. 52 restrictions but acceptable to the USPTO) are somewhat less likely to receive a grant of their financial patent application, although the result is not very significant.

Looking at the patent characteristics themselves, our hypothesis 3 stated that financial patents with few forward citations, many overlapping claims with earlier patents, and a large number of claims are less likely to be granted. All of this finds confirmation in the regression, and we fail to reject the hypothesis. In addition, both designating more states at the EPO and being a member of a large patent family increases the likelihood of a grant once a decision has been reached, even though both delay the decision. Again, this is consistent with greater effort by the patentee when more is at stake.

The final column reports on the predictors of opposition conditional on grant. Unfortunately, the sample size is fairly small and the results therefore somewhat weaker than some of those in the literature. It is noteworthy that patent owner characteristics do not predict the probability that a particular patent is opposed, with the exception of very young firms, who are less likely to be opposed, and German firms, who are more likely to be opposed. The main predictors of opposition are the number of forward cites received by the patent, and the family size, both of which are known to be significantly correlated with value, and the number of backward XY cites, which suggests that the opposition occurs because there is some controversy over the extent of the inventive step above a competitor's patent. An additional X or Y cite adds 2 per cent to the probability that a patent will be opposed, which is a large effect given the average opposition probability of 9 per cent for financial patents. ${ }^{22}$ The positive sign on claims adds further evidence in favor of the view that more complex, controversial patents are more likely to be opposed.

${ }^{21}$ In results not shown, when we combine the three ICT hardware sectors, we find that their probability of a grant is 0.15 higher than all other firms; the services sector probability is no different from that for other manufacturing firms.

${ }^{22}$ In unreported regressions we entered a variable that measure the grant lag (the lag between the time of application and grant time) in the opposition equation. This variable has a negative and significant impact on the likelihood of opposition. This effect can be due to the fact that a long lag allows the patent office and the applicant to negotiate important modifications of the original application that prevent oppositions. 
Hypothesis 4a stated that more valuable patents were more likely to be opposed: these results provide strong evidence that fails to reject this hypothesis. Hypothesis $4 \mathrm{~b}$, that more controversial patents are more likely to be opposed, is more weakly supported, possibly because our indicators (claims and XY backward cites) are somewhat weaker proxies for the underlying concept.

\section{[Table 5 about here]}

A better understanding of the relationship between value or importance, complexity or uncertain enforceability and opposition would require a more qualitative, in-depth analysis which goes beyond the scope of this paper. A casual inspection of our data, however, provides interesting insights about the opposition patterns. We found 106 oppositions to 53 financial patents that had a publication date 2000 or earlier. ${ }^{23}$ The analysis of opponents and defendants shows that a large share of oppositions has occurred within the financial and insurance sector. Financial patents owned by financial firms receive the largest number of oppositions (33), followed by patents owned by computer hardware and software firms (29). Over half the oppositions (65) come from German firms, which is similar to what was found by Harhoff and Hall (2005) for the cosmetics sector.

Most of the opposers come from the same sectors as the active patenters (computing hardware and software, finance and insurance, and post and telecommunications). By far the most active opposer is Giesecke \& Devrient (G\&D), a German supplier of banknote paper, banknote printing, currency automation systems, as well as smart cards and complex system solutions in the fields of telecommunications, electronic payment, health care, identification, transportation and IT security (PKI). This firm alone filed 21 oppositions to financial patents granted by the EPO, mostly during the first half of the 1990s. Recently, both Swisscom AG and Siemens have been active opposers. These data suggest that opposition involves mostly firms that contribute to financial innovation in various ways - from the development of new financial products and platforms to the creation of the equipment and telecom infrastructure that is needed to implement financial innovations. It is possible that they feel threatened by patents on technologies related to standards in this area; more detailed analysis awaits future work.

\footnotetext{
${ }^{23}$ For patents held by business firms, there were 100 oppositions to 53 patents, as in Table 5 .
} 


\section{Conclusions}

This paper presented a first look at the financial patents in the European Patent Office. It began by proposing a definition of such patents, drawing on earlier work using USPTO data. Although in the EPO system software 'as such' and business methods are excluded from the patentable subject matter, we found a substantial number of such patents in the European system. In principle, in order to be patentable at the EPO, these inventions should yield some technical effects and some financial inventions like payment technologies indeed have links with electronic (hardware) devices, such as wireless systems. However, it has often proved to be difficult to establish a clear border between patentable inventions and "pure" business methods.

Our investigation shows that financial patents are different from other patents in that they rely less on prior literature (patent or non-patent), and the literature they do rely on is younger, which is reasonable given their newness in the patent system. They also are slower to receive a decision at the EPO, which can reflect both the uncertainty surrounding a new and possibly unpatentable subject matter as well as the applicant behavior - i.e., her willingness to delay the disclosure of a valuable invention. Once a decision is reached, it is less likely to be a grant, and more likely to be opposed if it is. All this may reflect greater economic value, and we do find that financial patents have several indicators of higher value than other patents. The higher opposition rate may also be due to higher uncertainty surrounding these subject matters, especially in Europe.

Then we have explored the characteristics of financial patentees. First, firms from a few sectors (computers, telecommunication equipment, finance and insurance, and software) account for the bulk of financial patents. Second, large established firms maintain a large, albeit declining share of these patents while small, young firms have a smaller, but rising share of these patents. Small firms include some specialized technology firms whose business model is largely based on technology licensing. Nonetheless, to a great extent these patents are held by the same large firms (IBM, Siemens, Hitachi, etc) that hold the bulk of software patents at the EPO (Hall, Thoma, and Torrisi 2007).

Finally, we have analyzed how the main characteristics of the patentee and the invention impact on the outcome of the examiner's decision and probability of receiving an opposition. First we find that the probability of grant for financial patent applications - rather than reject (by 
the EPO) or withdrawal (by the applicant) - is influenced by the owner's stock of EPO patents, country of origin, and whether the applicant is in the computing sector (as opposed to the financial sector). This latter finding could reflect the relative lack of experience with patenting among financial firms. As expected, financial patent applications with more claims (a measure of complexity), or more XY-type backward cites (an indicator of limited inventive step) are less likely to be granted, whereas patent applications with a large number of equivalents in other jurisdictions (a measure of value) are far more likely to be granted.

The analysis of patent oppositions shows that patent-level characteristics including family size, forward citations, and XY type backward citations have a significant predictive power, but that the characteristics of the patent owner hardly matter. Our conclusion was the unsurprising one that more valuable financial patents were clearly more likely to be opposed. In addition, there was weaker evidence that more controversial financial patents were more likely to be opposed. Moreover, oppositions mostly involve, as opponents or as defendants, firms that are also important contributors to financial innovations and the underlying IT infrastructure. This result points to an important difference with the US system, where the most active plaintiffs in patent litigation are patent holder firms specializing in licensing and patent litigation (Lerner, 2006).

Our findings overall offer intellectual property managers and senior managers useful insights into financial innovations and patenting. Our analysis tells the type of financial patent applications which are more likely to affect the decision lag and the probability of a rejection at the EPO. They also point out which financial patents are more likely to be opposed and by whom. This evidence can help managers in elaborating their patenting strategies, increasing the probability of granting at the EPO, and economizing on post-grant litigation costs.

In conclusion, the explosion of patents in this field produces contrasting effects on social welfare. On the one side, the increased number of financial patents has induced more oppositions (and possibly more litigation costs as in the U.S.) and may to some extent be a byproduct of strategic patenting by large established computing firms. On the other side, financial patents open up new windows of opportunities for specialized technology firms. This trend is similar to what happens in other sectors such as security software and semiconductors (Giarratana, 2008; Hall and Ziedonis, 2001). In our future research we will explore more thoroughly the differences 
among the financial patents held by different types of firms. Moreover, we will examine the differences in patent exploitation strategies between specialized technology firms and vertically integrated firms. Our preliminary analysis shows that specialized technological firms are heavily involved in licensing out of their financial patents. 


\section{References}

Arora A., A. Fosfuri, and A. Gambardella (2001). Markets for Technology: The Economics of Innovation and Corporate Strategy. Cambridge, MA: MIT Press.

Arora A., A. Fosfuri, and A. Gambardella (2007). "Patents and the market for technology." In Maskus K. (ed.), Handbook of Intellectual Property Rights and Technical Change.

Bakels R., R. A. Ghosh, S. Torrisi, et al. (2008). Study of the effects of allowing patent claims for computerimplemented inventions. UNU-MERIT, the Netherlands: Final Report to the European Commission.

Barton, J.H. (2000). “Reforming the Patent System.” Science 287: 1933-1934.

Bessen, J. and Meurer, M.J. (2008). Patent Failure: How Judges, Bureaucrats, and Lawyers Put Innovators at Risk, Princeton, NJ: Princeton University Press.

Bresnahan, T. F., and Trajtenberg, M. (1995). "General purpose technologies: Engines of growth.” Journal of Econometrics 65: 83-108.

Cohen J. E., Lemley M.A. (2001). Patent Scope and Innovation in the Software Industry, http://www.georgetown.edu.

Cooter, R.D., and Rubinfeld, D.L. (1989). "Economic analysis of legal disputes and their resolutions." Journal of Economic Literature XXVII: 1067-1097.

Dreyfuss, R.C. (2001). "Examining State Street Bank: Developments in Business Method Patenting.” Computer und Recht International, 2001(1):1-9.

Duffy, J.F. Squires, J.A. (2008). “Disclosure and Financial Patents: Revealing the Invisible Hand.” Paper presented at the Bank of Finland-CEPR Conference, Helsinki, October 2008.

Gambardella A., D. Harhoff and B. Verspagen (2008). The value of European patents, European Management Review 5, 69-84

Giarratana M. (2007) Missing the starting gun: de alio entry order in new markets, inertia and real option capabilities, European Management Review 5: 115-124

Guellec, D. and B. Van Pottelsberghe de la Potterie (2000). "Applications, Grants, and the Value of Patent," Economic Letters 69 (1): 109-114.

Jaffe A. B. \& J. Lerner (2004). Innovation and Its Discontents: How Our Broken Patent System is Endangering Innovation and Progress, and What to Do About It. Princeton, NJ: Princeton University Press.

Janis, M.D. (1997). "Rethinking reexamination: Toward a viable administrative revocation system for U.S. patent law." Harvard Journal of Law and Technology 11: 1-122.

Hall, B. H. (2003). "Business method patents, innovation, and policy." Paper presented at the Financial Markets Conference of the Atlanta Federal Reserve Bank, Sea Island, Georgia, April 3-5, 2003. Cambridge, MA: NBER Working Paper No. W 9717.

Hall, B. H. (2007). "Innovation in non-bank payment systems." Paper presented at the Kansas City Federal Reserve Conference, Santa Fe, NM, May 2007.

Hall, B. H., and M. MacGarvie (2006). “The Private Value of Software Patents,” Cambridge, Mass.: NBER Working Paper 12195 (April).

Hall B. H., A. Jaffe, and M. Trajtenberg (2005). "Market value and patent citations." Rand Journal of Economics 36: 16-38. 
Hall. B. H., Thoma G., and Torrisi S. (2007). "The market value of patents and R\&D: Evidence from European firms.” Cambridge, MA: NBER Working Paper No. 13426.

Hall, B. H., and R. H. Ziedonis (2001). "The determinants of patenting in the U. S. semiconductor industry, 1980-1994.” Rand Journal of Economics 32: 101-128.

Harhoff, D., and B. H. Hall (2005). "Intellectual property strategy in the global cosmetics industry." LudwigMaxmilians-Universitaet Muenchen and CEPR; UC Berkeley and NBER: unpublished paper.

Harhoff, D., Narin, F., Scherer, F. M. and Vopel, K. (1999). "Citation frequency and the value of patented inventions." Review of Economics and Statistics 81: 511-515.

Harhoff, D., Scherer, F. M. and Vopel, K. (2003). "Citations, family size, opposition, and the value of patent rights." Research Policy 32: 1343-1364.

Harhoff, D. and Reitzig, M. (2004). "Determinants of opposition against EPO patent grants - The case of biotechnology and pharmaceuticals." International Journal of Industrial Organization 22: 443-480.

Harhoff D. and S. Wagner (2005). Modelling the duration of patent examination at the European Patent Office, CEPR Working Paper 5283

Heller, M. and R. Eisenberg (1998). "Can Patents Deter Innovation? The Anticommons in Biomedical Research,” Science, 280 May: 698-701.

Hunt, R. (2001). "You can patent that? Are patents on computer programs and business methods good for the New Economy?" Federal Reserve Bank of Philadelphia Business Review, $1^{\text {st }}$ Quarter: 5-15.

Hunt, R. (2008). "Business method patents and U.S. financial services.”, Federal Reserve Bank of Philadelphia Working Paper No. 08-10.

Lanjouw, J. O., and M. Schankerman (2001). "Characteristics of patent litigation: A window on competition." Rand Journal of Economics 32: 129-151.

Lanjouw, J. O., and M. Schankerman (2004a). "Protecting intellectual property rights: Are small firms handicapped?" The Journal of Law and Economics 47: 45-74.

Lanjouw, J. O., and M. Schankerman (2004b). "Patent quality and research productivity: Measuring innovation with multiple indicators." Economic Journal 114: 441-465.

Lazaridis G. and B. Van Pottelsberghe (2007). "The rigour of EPO's patentability criteria: An insight into the 'induced withdrawals'.” Brussels: Working Papers CEB 07-007.RS, Université Libre de Bruxelles, Solvay Business School, Centre Emile Bernheim (CEB).

Lemley, M. A. (2007). “Ten things to do about patent holdup of standards (and one not to)." Boston College Law Review 48: 1-49.

Lerner, J. (1994). "The importance of patent scope: An empirical analysis.” Rand Journal of Economics 25: 319-33.

Lerner, J. (2004). "The new new financial thing: The sources of innovation before and after State Street." Journal of Financial Economics 79: 223-255.

Lerner, J. (2006). “Trolls on State Street?: The litigation of financial patents, 1976-2005.” Boston, MA: Harvard Business School, manuscript.

Levine R. (1997). "Financial development and economic growth.” Journal of Economic Perspectives 35: 688-726.

Lunney, G.S., Jr. (2001). “e-Obviousness.” Michigan Telecommunications Technology Law Review 7: 363422. 
Managing Intellectual Property (2008). "EPO to address software patentability.” Weekly News, October 24.

Managing Intellectual Property (2008). "Federal Circuit clarifies test for business method patents." Weekly news, October 31.

Meyer, M. (1999). "Does science push technology? Patents citing scientific literature." Research Policy 29: 409- 434.

Putnam, J. (1996). The value of international patent rights. PhD Thesis, Yale University.

Quillen, C. D., O. H. Webster, and R. Eichmann (2002). "Continuing patent applications and performance of the U.S. Patent and Trademark Office - extended.” The Federal Circuit Bar Journal 12: 35-55

Rosenberg N. and Birdzell L.E. (1986). How The West Grew Rich: The Economic Transformation Of The Industrial World. New York: Basic Books Inc.

Scotchmer, S. (1996). "Protecting early innovators: Should second generation products be patentable? Rand Journal of Economics 27: 322-331.

Thoma, G. (2009). "Striving for a large market: evidence from a general purpose technology in action." Industrial and Corporate Change doi: 10.1093/icc/dtn050

Torrisi, S. (1989). Industrial Organisation and Innovation. An International Study of the Software Industry. Cheltenham: Edward Elgar.

Tufano, P. (1989). "Financial innovation and first-mover advantages." Journal of Financial Economics 25: 213-240.

Tufano, P. (2003). "Financial innovation." In Costantinides et al (eds), Handbook of the Economics of Finance. Amsterdam: Elsevier: 307-335.

Von Graevenitz, G., S. Wagner, and D. Harhoff (2008). "Incidence and growth of patent thickets - The impact of technological opportunities and complexity." London: CEPR Discussion Paper no. 6900.

Wagner, S. (2008). "Business method patents in Europe and their strategic use - Evidence from franking device manufacturers." Economics of Innovation and New Technology 17: 173-94.

Ziedonis, R. H. (2004). "Don't fence me in: Fragmented markets for technology and the patent acquisition strategies of firms." Management Science 50: 804-820. 


\section{Appendix A: Data and Sources}

Our analysis is based on multiple sources. The identification of financial patents based on ECLA codes and keywords has been done using the ESPACE on-line database. Bibliographic data on EPO patents have been extracted from the EPO-OECD PATSTAT database (October 2007 version), whereas information on oppositions was drawn from EPOLINE files.

For information on the patent owners we used a number of online company directories: Amadeus for European companies; Compustat for North American firms; Jade for Japanese and Who Owns Whom for other companies. We complemented these data with information from companies' websites.

\section{Selecting financial patents at the EPO}

As described in the text, our sample of financial patents is the union of patents selected using three different algorithms, intersected with patents selected using a set of financial processrelated keywords. Our methodology follows that used by Hall and MacGarvie (2007) to select software patents at the USPTO. The idea on which it is based is first to identify the universe in which such patents might lie using the relevant patent classification system and the patenting of "pure play" firms, and then to select from this universe by means of keywords those patents that are clearly related to the technology area and sector under consideration.

The first set of financial patents (Set A) relies on Hall (2007) and Lerner (2006), who defined a financial patent based on the subclasses of the US class 705 and 902 . We used a combination of those definitions obtaining a list of the following US class and subclasses: 705/14; 705/16-18; 705/21; 705/33; 705/35-45; 705/53-56; 705/61; 705/64-79; 902/1-41. For more details see Appendix 1. Then we retrieved all the documents in the USPTO assigned to at least one of those class and subclass combinations. We obtained a sample of 9,549 utility patent documents granted in the USPTO, that correspond to about 1,350 equivalents of patent applications in EPO. ${ }^{24}$ A similar approach has been followed by Wagner (2008) to find EPO patents on business methods. Note that the use of this criterion by itself to identify a financial patent in EPO has the limitation of excluding EPO applications with no equivalent application

\footnotetext{
${ }^{24}$ For the US patent documents the source is www.uspto.gov, visited August $16^{\text {th }}, 2008$; for the EPO equivalents we used PATSTAT version October 2007. There is a lag of approximately 1.5 years between the release of PATSTAT and the documents retrieved from the USPTO website.
} 
filed in the USPTO or with an equivalent US application which has been rejected or not yet granted.

The second method of defining a financial patent at the EPO relied on other patent classification systems, the IPC and the ECLA systems (Set B). We started by retrieving all patent documents classified in the full digit IPCs corresponding to the above US classes and subclasses according to the USPC-to-IPC Concordance Table provided by the USPTO. ${ }^{25}$ The validity of this task is hampered by the fact there is a many-to-many correspondence across the IPC and USPC. Hence, in order to check that these IPCs are appropriate for identifying financial patents, we consider how many other subclasses not identified by 705/902 end up in the same full digit IPCs. We found that no full digit IPC is related one-for-one to the US classes and subclasses of financial patents defined by Hall (2007) and Lerner (2006). The IPCs either include subclasses different from the US 705 subclasses considered by Hall and Lerner (e.g., IPC class G06F/11/34 corresponds to USPC class 705/11 which is about "job performance analysis") or they are linked to other U.S. classes such as $235,186,178,380$, which are not related with financial inventions. Hence, the use of the IPC classes only for defining a financial patent could generate some false positives.

Therefore we employed an extension of the IPC - the ECLA classification - which is administrated by the EPO and is about twice as detailed as the IPC. ${ }^{26}$ On the one hand, we used the Concordance Table provided by the USPTO (see previous paragraph) to choose the ECLA codes related to the IPCs corresponding the USPC classes of Hall (2007) and Lerner (2006). On the other hand we identified those ECLA codes in which the EPO equivalents of the US financial patents were classified. In particular we considered the top ten groups of ECLA codes which contain about 78 per cent of the EPO equivalents of the US financial patents. This yielded the following ECLA codes for identifying financial system-related patents at the EPO (for the description see Table A.5): G06Q20/00; G06F21/00N9A2P; G07F7/02; G07F7/08; G07F7/10D; G07F7/10E; and H04L9/32. This subset of patents consists of circa 2,803 patent documents which are referred to as SET B in Table 1.

\footnotetext{
${ }^{25}$ See http://www.uspto.gov/go/classification/international/ipc/ipc8/ipc_concordance/ipcsel.htm

${ }^{26}$ For more information on the ECLA classification see:

http://ep.espacenet.com/help?topic=classesqh\&locale=en_EP\&method=handleHelpTopic
} 
The third criterion used to define a financial patent was based on an analysis of the patenting activity of 'pure play' firms, that is, firms that specialize in financial services or software. To identify pure play firms we started with a list provided by Hall (2007) for the US patentees, and for the largest European patentees we considered those classified in investment banking and securities dealing (NAICS activity 523110). ${ }^{27}$ We then retrieved all patent applications filed by these firms in the EPO. We found about 452 patents that could potentially be related to financial innovations, because they were filed by firms specializing in financial services. To these we added all patents having the same class/subclass areas where the chosen set of "pure play" firms patent, as was done by Graham and Mowery (2004). This group consisted of 85,542 EPO patents labeled as SET C in Table 1.

Table A.1: Number of patents in each set and their intersection sets

\begin{tabular}{|l|c|c|c|}
\hline & SET A & SET B & SET C \\
\hline SET A & 1350 & 217 & 927 \\
\hline SET B & 217 & 2803 & 1425 \\
\hline SET C & 927 & 1425 & 85,994 \\
\hline
\end{tabular}

Source: Our elaborations using USPTO and EPO datasets

The results of this complex search procedure are illustrated in Table A.1. The union of the three search criteria yields 87,719 patent applications at the EPO, whereas the intersection yields only 141 patents. The largest similarity across methods is obtained when SET A and SET $\mathrm{B}$ are taken together, yielding an intersection of about 217 patents, accounting for $16.1 \%$ of patents in SET A and 7.7\% in SET B. Moreover, there is a very small intersection between SET $\mathrm{C}$ and the other two sets. This evidence points to the fact that the three search methods may include patents unrelated to financial innovations, and also that most of these patents are not held by pure play firms.

Hence, to minimize the number of false positives (Type I error) at this preliminary stage of the analysis, we analyzed the text of the titles and abstracts of the selected patents and

\footnotetext{
${ }^{27}$ For European firms we considered only NAICS 523110 because the other NAICS related to market of financial services are characterized by the presence of many holding companies of large industrial groups.
} 
restricted our sample only to patent documents having as words or sub-words (e.g., wallet in electronic-wallet) at least one these keywords: transaction, financial, credit, payment, money, debit card, portfolio, and wallet.

After this further refining of financial patent definition, our sample was reduced to about 3,446 patent applications at the EPO (see Table A.2). This constitutes the final set of financial patents. Note that the table shows a greater similarity across the results obtained with the three different definitions.

Table A.2: Including financial keywords in the title and abstract

\begin{tabular}{|c|c|c|c|}
\hline & SET A & SET B & SET C \\
\hline SET A & 362 & 119 & 274 \\
\hline SET B & 119 & 944 & 591 \\
\hline SET C & 274 & 591 & 3,039 \\
\hline
\end{tabular}

Source: Our elaborations using USPTO and EPO datasets

The sample actually used in estimation was slightly reduced to 3,298 patents by restricting the priority year to be prior to 2006, and removing a few patents for whom we did not know the applicant name or type (Table A.3).

Table A.3: Selecting the sample

\begin{tabular}{|l|r|}
\hline $\begin{array}{l}\text { Total number of financial patents on the } \\
\text { Oct 2007 PATSTAT }\end{array}$ & 3,446 \\
\hline $\begin{array}{l}\text { Less loss due to slight change in Set B } \\
\text { (no bibliometric information) }\end{array}$ & -17 \\
\hline Less patents with priority year $>2005$ & -40 \\
\hline Missing applicant code & -97 \\
\hline Other & -4 \\
\hline Sample of financial patents & $\mathbf{3 , 2 9 8}$ \\
\hline
\end{tabular}


Finally, in order to fully access the different kind of patents identified by the above searching strategy we read the titles, abstracts and the description of the patent documents. In particular we classified them using a similar taxonomy to that suggested by Duffy and Squires (2008) consisting of the following categories:

1) ATM (Automatic Teller Machine), mechanical or electronic technologies that have some connection to the financial industry

2) Trading technologies including anti-fraud techniques, mechanisms for implementing trades, and trading structures and market microstructure. This also includes web transaction methods.

3) Valuation techniques or other financial strategies

4) Financial products, broadly construed to include sophisticated products such as a new credit default swap or a more consumer oriented product.

We selected for reading the patent documents in SET A that had received a final decision, that is a Grant, Withdrawal or Rejection. The goal of this choice was two-fold: On the one hand, the patents of SET A have by definition an equivalent in USPTO, which ensures potential comparability with current and future studies on the US patents. On the other hand, considering only those that have received a final decision allows us to document which technologies are considered patentable by the EPO.

As we can see from Table A.4, a large share of the patents analyzed are in category (2), which relates to the methods and technologies for implementing transactions and payments systems. In one sense, Table A.4 helps to validate the keywords search algorithm proposed above, as we found almost no patents in SET A that were unrelated to finance and payments methods. In the same vein, there is little evidence of the presence of advanced financial engineering methods in the SET A patents. Thus we conclude that the methodology proposed provides a fairly robust definition for selecting patents related to technologies for trading and payment systems at the EPO. 
Table A.4 Financial patents by type of the technologies involved

\begin{tabular}{lcccccc}
\hline & \multicolumn{2}{c}{ Granted } & \multicolumn{2}{c}{ Rejected } & \multicolumn{2}{c}{ Withdrawn } \\
Category & Number & Share & Number & Share & Number & Share \\
\hline (1) ATM, etc. & 14 & $14.7 \%$ & 3 & $12.0 \%$ & 13 & $10.2 \%$ \\
(2) Trading & 72 & $75.8 \%$ & 12 & $48.0 \%$ & 94 & $74.0 \%$ \\
(3) Valuation & 9 & $9.5 \%$ & 6 & $24.0 \%$ & 20 & $15.7 \%$ \\
(4) Fin prods & 0 & $0.0 \%$ & 4 & $16.0 \%$ & 0 & $0.0 \%$ \\
Overall & 95 & $100.0 \%$ & 25 & $100.0 \%$ & 127 & $100.0 \%$ \\
\hline
\end{tabular}

Sources: The taxonomy is based on Duffy and Squires (2008)

Notes: (1) ATM's or mechanical or electronic technologies that have some connection to the financial industry;(2) Trading technologies including anti-fraud techniques, mechanisms for implementing trades, and trading structures and market microstructure. This includes also the web transactions; (3) Valuation technique or other financial strategy; (4) Financial products, broadly construed to include sophisticated products such as a new credit default swap or a more consumer oriented product. 
Table A.5: List of ECLA classes with financial patents

\begin{tabular}{ll}
\hline $\mathbf{N}$ & ECLA subclass \\
\hline 12 & G06Q20/00
\end{tabular}

13 G06Q20/00K further characterised by the type of neutral party arbitrating, type of payment Description

Payment schemes, architectures or protocols(apparatus for performing or posting payment transactions circuit used, architecture used, payment model or scheme applied, or details of specific step in the protocol

14 G06Q20/00K1 involving a neutral party, e.g. certification authority, notary or trusted third party (TTP)

15 G06Q20/00K2 characterised by the type of payment circuit

16 G06Q20/00K2B in a public payment circuit, e.g. standard banking accounts

17 G06Q20/00K2C in a private payment circuit, e.g. electronic cash used only among participants of a common payment scheme or inside a defined community, money generated by private organizations

18 G06Q20/00K3 characterised by the architecture used

19 G06Q20/00K3A Electronic funds transfer (EFT) systems; Home banking systems

20 G06Q20/00K3B Electronic shopping systems

21 G06Q20/00K3C Billing systems

22 G06Q20/00K3D Payments settled via telephone service provider

23 G06Q20/00K3E Payments for services accessed through systems involving a self- service

24 G06Q20/00K3F point-of-sale (POS) network systems (POS per se G07F or G07G)

25 G06Q20/00K4 characterised by the payment model or scheme

26 G06Q20/00K4C Credit card scheme, e.g. pay after

27 G06Q20/00K4D Debit scheme, e.g. pay now

28 G06Q20/00K4P Pre-payment scheme, e.g. pay before

29 G06Q20/00K5 characterised by the use of a wireless device

30 G06Q20/00K6 characterised by details of the protocol

31 G06Q20/00K6A Authorisation

32 G06Q20/00K6C Confirmation

61 G06F21/00 Security arrangements for protecting computers or computer systems against unauthorised activity(multiprogrammingG06F9/46; protection against unauthorised use of memoryG06F12/14; dispensing apparatus actuated by coded identity card or credit cardG07F7/08;

142 G06F21/00N9A2P ... protecting personal data, e.g. for financial or medical purposes

154 G07F7/00 Mechanisms actuated by objects other than coins to free or to actuate vending, hiring, coin or paper currency dispensing or refunding apparatus (handling coins or paper currencies apart from coin-freed or like apparatus G07D; complete banking systems G07F

159 G07F7/02 by keys or other credit registering devices (for producing a coded signal for use together with coded identity cards G07F7/10)

160 G07F7/02B

... by active credit-registering devices, e.g. counters, memories

$161 \mathrm{G} 07 \mathrm{~F} 7 / 02 \mathrm{C}$

... by means, e.g. cards, comprising cases representing monetary value (for cancelling tickets, see G07B11/11)

162 G07F7/02D ... by cards with numerical value (G07F7/08 takes precedence) 
163 G07F7/02E

170 G07F7/08

171 G07F7/08B

172 G07F7/08C

173 G07F7/08C2

174 G07F7/08C2B

175 G07F7/08C2C

176 G07F7/08C4

177 G07F7/08C6

$178 \mathrm{G} 07 \mathrm{~F} 7 / 08 \mathrm{C} 8$

179 G07F7/08D

180 G07F7/08E

181 G07F7/08E2

182 G07F7/08E4

$183 \mathrm{G} 07 \mathrm{~F} 7 / 08 \mathrm{~F}$

184 G07F7/08F2

$185 \mathrm{G} 07 \mathrm{~F} 7 / 08 \mathrm{~F} 4$

192 G07F7/10D

193 G07F7/10D2

194 G07F7/10D2K

195 G07F7/10D2M

196 G07F7/10D2P

197 G07F7/10D4

198 G07F7/10D4E

199 G07F7/10D4E2

200 G07F7/10D4T

201 G07F7/10D6

202 G07F7/10D6F
... by means, e.g. cards, providing billing information at the time of purchase, e.g. identification of seller or purchaser, quantity of goods delivered or to be delivered]

by coded identity card or credit card ... or other personal identification means(without personal verification meansG07F7/02)

... by passive credit-cards adapted therefore : constructive particularities to avoid counterfeiting, e.g. by inclusion of a physical or chemical security-layer (for security documents see G07D7/00; for the reading of record-carriers in general see G06K7/

... by active credit-cards adapted therefor (G07F7/10D takes precedence)

... Electronic wallets suitable to be connected to similar devices for mutual funds transfer, either with or without a terminal

... with central accounting to keep track of the electronic money in circulation

... the wallets having several accounts

... the value being automatically decremented in function of a variable, e.g. time, distance

... Systems wherein such cards are used for payment

... Separate devices accepting such cards for payment

... Details or accessories, e.g. reading, decoding, printing of data from the cards (G06K takes precedence)

... Verification of the card, i.e. checking validity to avoid misuse, e.g. checking expiry date

... by comparing with other document or pass, e.g. with a bank-cheque

... by mutual comparing codes on the card

... Account status verification, e.g. checking solvency of the holder (computers adapted for financial accounting G06Q40/00A)

... Local credit-checking, e.g. with black-list on tape

... Central credit-checking via terminal (G07F7/10 takes precedence)

... Active credit-cards provided with means to personalise their use, e.g. with PIN-introduction/comparison system

... Personalisation or initialisation of card

... with securisation during issuing/transport phase

... for several users, e.g. hierarchical

... by application program downloading (G07F7/10D10M2 takes precedence)

... Mutual authentication of card and transaction partner, e.g. terminal, host, other card

... the card having encyphering/decyphering capabilities

... used for an authentication protocol (means for verifying the identity or authority of the user of a communication system per se H04L9/32)

... with transaction monitoring means, e.g. deriving transaction authentication number; with registration of transaction

... Identification of card user

... with means to protect against fraudulent identification attempts, e.g. counter for erroneous PIN-attempts 
203 G07F7/10D6K

204 G07F7/10D6P

205 G07F7/10D8

206 G07F7/10D8C

207 G07F7/10D8P

208 G07F7/10D10

209 G07F7/10D10M

210 G07F7/10D10M2

211 G07F7/10D12

\section{G07F7/10D14}

213 G07F7/10D16

214 G07F7/10E

260 H04L9/32

$\begin{array}{ll}261 & \text { H04L9/32A } \\ 262 & \text { H04L9/32B } \\ 263 & \text { H04L9/32C } \\ 264 & \text { H04L9/32H } \\ 265 & \text { H04L9/32M } \\ 266 & \text { H04L9/32P } \\ 267 & \text { H04L9/32R } \\ 268 & \text { H04L9/32R2 } \\ 269 & \text { H04L9/32R4 } \\ 270 & \text { H04L9/32S } \\ 271 & \text { H04L9/32S1 } \\ 272 & \text { H04L9/32S3 } \\ 273 & \text { H04L9/32S5 } \\ 274 & \text { H04L9/32S5P } \\ 275 & \text { H04L9/32T }\end{array}$

... by comparing other identifying data with reference data stored in the card chip (G07C9/00B6 takes precedence)

... by PIN check

... Independent cards, capable to authorise a transaction without the intervention of a terminal, e.g. by self-checking of user identity or solvency

... Cards only used as intermediate carriers for identification data of user and for transaction data

... Cards combined with portable reader/writer to constitute an independent assembly

... Multiple service cards, e.g. for several accounts, applications of the same person, the card to be processed by different terminals/issuers

... with protecting memory zones, assigned to one service, against access

(read/write/delete) by terminals of other services (protection against

unauthorised access of computer memory areas in general G06F12/14; circuits for protecting data, e.g. PIN, in

... Zone-allocation and setting access conditions of zones

... Means to guarantee integrity of card data, not provided for in G07F7/10D2

to G07F7/10D10, e.g. digital signatures, check numbers

... Details or accessories concerning data transfer and storing, e.g. error detection, self diagnosis (G06K19/07 takes precedence)

... Multiple-card systems, the cards having either different or identical

... Devices and methods for securing the PIN and other transaction-data, e.g. by encryption (arrangements for secret communication, see H04L9/00)

Arrangements for secret or secure communication

including means for verifying the identity or authority of a user of the system (computer systems G06F; coin-freed or like apparatus with coded identity card or credit card G07F7/08)

involving a third party or a trusted authority

using a non-public key algorithm

using a zero-knowledge proof

using hash functions

for message authentication (H04L9/32S takes precedence)

involving the concurrent use of a plurality of channels of different nature

using challenge-response

for mutual authentication

involving splitting up or repeating the challenge and/or response

using electronic signatures

using blind signatures

involving a plurality or a group of signers

with message recovery

with partial message recovery

using time stamps or public key certificates

\section{Appendix B: Additional Figures and Tables}


Table B.1: Time evolution of EPO financial patents by region of the patentee 3,127 EPO patent documents*

\begin{tabular}{|c|c|c|c|c|c|}
\hline \multirow[b]{2}{*}{ Country } & \multicolumn{5}{|c|}{ Number with priority year equal to } \\
\hline & before 1990 & 1990-1994 & 1995-99 & $2000-2005$ & Total \\
\hline US & 85 & 109 & 594 & 771 & 1559 \\
\hline Germany & 17 & 14 & 68 & 202 & 301 \\
\hline France & 23 & 23 & 60 & 100 & 206 \\
\hline$U K$ & 17 & 3 & 30 & 86 & 136 \\
\hline Other EU countries & 18 & 18 & 120 & 260 & 416 \\
\hline EU27 total & 75 & 58 & 278 & 648 & 1059 \\
\hline Japan & 24 & 25 & 129 & 219 & 397 \\
\hline Rest of world & 8 & 4 & 28 & 72 & 112 \\
\hline \multirow[t]{2}{*}{ Overall } & 192 & 196 & 1029 & 1710 & 3127 \\
\hline & \multicolumn{5}{|c|}{ Shares with priority year equal to } \\
\hline Country & before 1990 & 1990-1994 & 1995-99 & $2000-2005$ & Total \\
\hline US & $44.3 \%$ & $55.6 \%$ & $57.7 \%$ & $45.1 \%$ & $49.9 \%$ \\
\hline Germany & $8.9 \%$ & $7.1 \%$ & $6.6 \%$ & $11.8 \%$ & $9.6 \%$ \\
\hline France & $12.0 \%$ & $11.7 \%$ & $5.8 \%$ & $5.8 \%$ & $6.6 \%$ \\
\hline$U K$ & $8.9 \%$ & $1.5 \%$ & $2.9 \%$ & $5.0 \%$ & $4.3 \%$ \\
\hline Other EU countries & $9.4 \%$ & $9.2 \%$ & $11.7 \%$ & $15.2 \%$ & $13.3 \%$ \\
\hline EU27 total & $39.1 \%$ & $29.6 \%$ & $27.0 \%$ & $37.9 \%$ & $33.9 \%$ \\
\hline Japan & $12.5 \%$ & $12.8 \%$ & $12.5 \%$ & $12.8 \%$ & $12.7 \%$ \\
\hline Rest of world & $4.2 \%$ & $2.0 \%$ & $2.7 \%$ & $4.2 \%$ & $3.6 \%$ \\
\hline
\end{tabular}

*245 documents have more than one applicant but in all cases the applicants are from the same country. Source: our computations, see text for details. 
Table B.2: Time evolution of US financial patents by region of the patentee

Financial Patents based on Hall (2007) and Lerner (2006) classes plus financial keywords 4,460 US utility patent documents*

\begin{tabular}{lrrrrr}
\hline \multicolumn{5}{c}{ Number with priority year equal to } & \\
\hline Country & before 1990 & $\mathbf{1 9 9 0 - 1 9 9 4}$ & $\mathbf{1 9 9 5 - 9 9}$ & after 2000 & Total* \\
\hline US & 392 & 1829 & 283 & 1040 & 3544 \\
Germany & 15 & 16 & 6 & 6 & 43 \\
France & 19 & 27 & 12 & 6 & 64 \\
UK & 21 & 26 & 12 & 12 & 71 \\
Other EU countries & 11 & 52 & 8 & 42 & 113 \\
EU27 total & 66 & 121 & 38 & 66 & 291 \\
JP & 179 & 144 & 51 & 75 & 449 \\
Rest of world & 23 & 90 & 16 & 73 & 202 \\
Overall* & 660 & 2184 & 388 & 1254 & 4486 \\
\hline & & Shares with priority year equal to & \\
\hline Country & $\mathbf{4}$ & $\mathbf{1 9 9 0 - 1 9 9 4}$ & $\mathbf{1 9 9 5 - 9 9}$ & after 2000 & Total \\
\hline US & $5.4 \%$ & $83.7 \%$ & $72.9 \%$ & $82.9 \%$ & $79.0 \%$ \\
Germany & $2.3 \%$ & $0.7 \%$ & $1.5 \%$ & $0.5 \%$ & $1.0 \%$ \\
France & $2.9 \%$ & $1.2 \%$ & $3.1 \%$ & $0.5 \%$ & $1.4 \%$ \\
UK & $3.2 \%$ & $1.2 \%$ & $3.1 \%$ & $1.0 \%$ & $1.6 \%$ \\
Other EU countries & $1.7 \%$ & $2.4 \%$ & $2.1 \%$ & $3.3 \%$ & $2.5 \%$ \\
EU27 total & $10.0 \%$ & $5.5 \%$ & $9.8 \%$ & $5.3 \%$ & $6.5 \%$ \\
JP & $27.1 \%$ & $6.6 \%$ & $13.1 \%$ & $6.0 \%$ & $10.0 \%$ \\
Rest of world & $3.5 \%$ & $4.1 \%$ & $4.1 \%$ & $5.8 \%$ & $4.5 \%$ \\
\hline
\end{tabular}

*292 documents have more than one applicant but in almost all cases the applicants are from the same country.

Source: PATSTAT October 2007 
Table B.3: EPO financial patents by the sector and age of the patentee

2,945 EPO patent documents*

\begin{tabular}{|c|c|c|c|c|c|c|c|c|}
\hline \multirow[b]{2}{*}{$\begin{array}{c}\text { Stan } \\
\text { Code }\end{array}$} & \multirow[b]{2}{*}{ Sector Description } & \multicolumn{7}{|c|}{ Founding year of firm } \\
\hline & & pre-1970 & $\begin{array}{c}1971- \\
1980 \\
\end{array}$ & $\begin{array}{c}1981- \\
1990 \\
\end{array}$ & $\begin{array}{c}1991- \\
1995 \\
\end{array}$ & $\begin{array}{c}1996- \\
2000 \\
\end{array}$ & $\begin{array}{c}2001- \\
2005 \\
\end{array}$ & Unknown \\
\hline 17 & Office, accounting, computing machinery & 492 & 44 & 67 & 5 & 4 & 8 & 4 \\
\hline \multirow[t]{2}{*}{19} & Radio, television \& comm. equipment & 173 & 5 & 30 & 6 & 8 & 4 & 0 \\
\hline & Equipment & 665 & 49 & 97 & 11 & 12 & 12 & 4 \\
\hline 38 & Finance \& insurance & 325 & 6 & 25 & 60 & 61 & 40 & 15 \\
\hline 41 & Software \& computer related activities & 40 & 57 & 130 & 72 & 134 & 135 & 2 \\
\hline 37 & Post \& telecommunications & 125 & 0 & 91 & 23 & 39 & 12 & 0 \\
\hline \multirow[t]{2}{*}{43} & Other business services & 38 & 1 & 53 & 16 & 42 & 75 & 2 \\
\hline & Services & 528 & 64 & 299 & 171 & 276 & 262 & 19 \\
\hline \multirow[t]{4}{*}{-} & Other business sectors & 377 & 12 & 43 & 29 & 36 & 25 & 7 \\
\hline & Sector unknown & 0 & 0 & 0 & 1 & 1 & 0 & 9 \\
\hline & Total & 1570 & 125 & 439 & 212 & 325 & 299 & 39 \\
\hline & & \multicolumn{7}{|c|}{ Within-sector shares of financial-patenting firms founded in each period } \\
\hline 17 & Office, accounting, computing machinery & $78.8 \%$ & $7.1 \%$ & $10.7 \%$ & $0.8 \%$ & $0.6 \%$ & $1.3 \%$ & $0.6 \%$ \\
\hline \multirow[t]{2}{*}{19} & Radio, television \& comm. equipment & $76.5 \%$ & $2.2 \%$ & $13.3 \%$ & $2.7 \%$ & $3.5 \%$ & $1.8 \%$ & $0.0 \%$ \\
\hline & Equipment & $78.2 \%$ & $5.8 \%$ & $11.4 \%$ & $1.3 \%$ & $1.4 \%$ & $1.4 \%$ & $0.5 \%$ \\
\hline 38 & Finance \& insurance & $61.1 \%$ & $1.1 \%$ & $4.7 \%$ & $11.3 \%$ & $11.5 \%$ & $7.5 \%$ & $2.8 \%$ \\
\hline 41 & Software \& computer related activities & $7.0 \%$ & $10.0 \%$ & $22.8 \%$ & $12.6 \%$ & $23.5 \%$ & $23.7 \%$ & $0.4 \%$ \\
\hline 37 & Post \& telecommunications & $43.1 \%$ & $0.0 \%$ & $31.4 \%$ & $7.9 \%$ & $13.4 \%$ & $4.1 \%$ & $0.0 \%$ \\
\hline \multirow[t]{2}{*}{43} & Other business services & $16.7 \%$ & $0.4 \%$ & $23.3 \%$ & $7.0 \%$ & $18.5 \%$ & $33.0 \%$ & $0.9 \%$ \\
\hline & Services & $32.6 \%$ & $4.0 \%$ & $18.5 \%$ & $10.6 \%$ & $17.0 \%$ & $16.2 \%$ & $1.2 \%$ \\
\hline \multirow[t]{2}{*}{-} & Other business sectors & $71.3 \%$ & $2.3 \%$ & $8.1 \%$ & $5.5 \%$ & $6.8 \%$ & $4.7 \%$ & $1.3 \%$ \\
\hline & Sector unknown & $0.0 \%$ & $0.0 \%$ & $0.0 \%$ & $9.1 \%$ & $9.1 \%$ & $0.0 \%$ & $81.8 \%$ \\
\hline
\end{tabular}

*The sample includes double counting in case of copatenting and excludes patents held by individuals and governments. There are 52 patents with more than one applicant. 


\begin{tabular}{|c|c|c|c|c|c|}
\hline \multicolumn{6}{|c|}{$\begin{array}{l}\text { Table B.4: Time evolution of financial patents by size of the patentee } \\
2,945 \mathrm{EPO} \text { patent documents* }\end{array}$} \\
\hline \multirow[b]{2}{*}{ Size of firm } & \multicolumn{5}{|c|}{\begin{tabular}{|c|} 
With priority year equal to \\
\end{tabular}} \\
\hline & before 1990 & 1990-1994 & 1995-99 & 2000-2005 & Overall \\
\hline & \multicolumn{5}{|c|}{ Number of patents } \\
\hline Large (>249 employees) & 130 & 151 & 800 & 1,191 & 2272 \\
\hline Medium (50-249 employees) & 13 & 16 & 63 & 114 & 206 \\
\hline Small (<50 employees) & 33 & 25 & 138 & 329 & 525 \\
\hline Size class not available & 0 & 1 & 1 & 4 & 6 \\
\hline \multirow[t]{2}{*}{ Total } & 176 & 193 & 1002 & 1638 & 3009 \\
\hline & \multicolumn{5}{|c|}{ Share of patents by size of firm } \\
\hline Large (>249 employees) & $73.9 \%$ & $78.2 \%$ & $79.8 \%$ & $72.7 \%$ & $75.5 \%$ \\
\hline Medium (50-249 employees) & $7.4 \%$ & $8.3 \%$ & $6.3 \%$ & $7.0 \%$ & $6.8 \%$ \\
\hline Small (<50 employees) & $18.8 \%$ & $13.0 \%$ & $13.8 \%$ & $20.1 \%$ & $17.4 \%$ \\
\hline Size class not available & $0.0 \%$ & $0.5 \%$ & $0.1 \%$ & $0.2 \%$ & $0.2 \%$ \\
\hline
\end{tabular}

*The sample includes double counting in case of copatenting and excludes patents held by individuals and governments. There are 52 patents with more than one applicant. 
Table B.5: EPO financial patents by the size and age of the patenting firm 2,945 EPO patent documents*

\section{Size of firm}

\begin{tabular}{lccccc} 
Founding Year & Large & Medium & Small & $\begin{array}{c}\text { Size } \\
\text { unknown }\end{array}$ & Total \\
\hline \multicolumn{7}{c}{ Number of patents } \\
pre-1970 & 1559 & 5 & 6 & 0 & 1570 \\
$1971-1980$ & 115 & 7 & 3 & 0 & 125 \\
$1981-1990$ & 370 & 25 & 44 & 0 & 439 \\
$1991-1995$ & 127 & 38 & 47 & 0 & 212 \\
$1996-2000$ & 78 & 99 & 148 & 0 & 325 \\
$2001-2005$ & 15 & 25 & 259 & 0 & 299 \\
Not known & 8 & 7 & 18 & 6 & 39 \\
Total & 2272 & 206 & 525 & 6 & 3009 \\
\hline \multicolumn{5}{c}{} & \multicolumn{5}{c}{ Shares by size in each founding period } & \\
\hline pre-1970 & $99.3 \%$ & $0.3 \%$ & $0.4 \%$ & $0.0 \%$ & \\
$1971-1980$ & $92.0 \%$ & $5.6 \%$ & $2.4 \%$ & $0.0 \%$ & \\
$1981-1990$ & $84.3 \%$ & $5.7 \%$ & $10.0 \%$ & $0.0 \%$ & \\
$1991-1995$ & $59.9 \%$ & $17.9 \%$ & $22.2 \%$ & $0.0 \%$ & \\
$1996-2000$ & $24.0 \%$ & $30.5 \%$ & $45.5 \%$ & $0.0 \%$ & \\
$2001-2005$ & $5.0 \%$ & $8.4 \%$ & $86.6 \%$ & $0.0 \%$ & \\
Not known & $20.5 \%$ & $17.9 \%$ & $46.2 \%$ & $15.4 \%$ & \\
\hline
\end{tabular}

*The sample includes double counting in case of copatenting and excludes patents held by individuals and governments. There are 52 patents with more than one applicant. 
Table 1: Patents by the country and sector of the patentee

\begin{tabular}{|c|c|c|c|c|c|c|c|}
\hline \multirow[b]{2}{*}{ Code+ } & \multirow[b]{2}{*}{ Sector Description } & \multicolumn{2}{|c|}{ Overall } & \multicolumn{2}{|c|}{$\boldsymbol{E U} 27$} & \multicolumn{2}{|c|}{$U S$} \\
\hline & & $N$ & Share* & $N$ & Share* & $N$ & Share* \\
\hline 17 & Office, accounting \& computing machinery & 624 & $20.8 \%$ & 45 & $4.5 \%$ & 378 & $25.3 \%$ \\
\hline 41 & Computer services \& related activities & 570 & $19.0 \%$ & 212 & $21.3 \%$ & 323 & $21.6 \%$ \\
\hline 38 & Finance \& insurance & 532 & $17.7 \%$ & 106 & $10.7 \%$ & 388 & $26.0 \%$ \\
\hline 37 & Post \& telecommunications & 290 & $9.7 \%$ & 182 & $18.3 \%$ & 67 & $4.5 \%$ \\
\hline 43 & Other business services & 227 & $7.6 \%$ & 69 & $6.9 \%$ & 132 & $8.8 \%$ \\
\hline 19 & Radio, television \& communication equip. & 226 & $7.5 \%$ & 123 & $12.4 \%$ & 47 & $3.1 \%$ \\
\hline 18 & Electrical machinery \& apparatus, nec & 162 & $5.4 \%$ & 108 & $10.9 \%$ & 6 & $0.4 \%$ \\
\hline 20 & Medical, precision \& optical instruments & 91 & $3.0 \%$ & 44 & $4.4 \%$ & 23 & $1.5 \%$ \\
\hline 31 & Wholesale \& retail trade repairs & 65 & $2.2 \%$ & 33 & $3.3 \%$ & 23 & $1.5 \%$ \\
\hline 16 & Machinery \& equipment, nec & 60 & $2.0 \%$ & 23 & $2.3 \%$ & 28 & $1.9 \%$ \\
\hline 9 & Chemicals excluding pharmaceuticals & 24 & $0.8 \%$ & 1 & $0.1 \%$ & 22 & $1.5 \%$ \\
\hline 7 & Pulp, paper products, printing and publishing & 21 & $0.7 \%$ & 18 & $1.8 \%$ & 1 & $0.1 \%$ \\
\hline 46 & Health \& social work & 11 & $0.4 \%$ & 0 & $0.0 \%$ & 10 & $0.7 \%$ \\
\hline 21 & Motor vehicles, trailers \& semi-trailers & 10 & $0.3 \%$ & 3 & $0.3 \%$ & 2 & $0.1 \%$ \\
\hline 8 & Coke, petroleum products \& nuclear fuel & 9 & $0.3 \%$ & 0 & $0.0 \%$ & 6 & $0.4 \%$ \\
\hline 35 & Air transport & 9 & $0.3 \%$ & 2 & $0.2 \%$ & 6 & $0.4 \%$ \\
\hline 25 & Manufacturing nec recycling (in. Furniture) & 8 & $0.3 \%$ & 1 & $0.1 \%$ & 5 & $0.3 \%$ \\
\hline 23 & Aircraft \& spacecraft & 7 & $0.2 \%$ & 1 & $0.1 \%$ & 6 & $0.4 \%$ \\
\hline 47 & Other community, social \& personal services & 7 & $0.2 \%$ & 4 & $0.4 \%$ & 2 & $0.1 \%$ \\
\hline 4 & Food products, beverages and tobacco & 6 & $0.2 \%$ & 1 & $0.1 \%$ & 5 & $0.3 \%$ \\
\hline 33 & Land transport transport via pipelines & 6 & $0.2 \%$ & 1 & $0.1 \%$ & 3 & $0.2 \%$ \\
\hline 42 & Research \& development & 6 & $0.2 \%$ & 3 & $0.3 \%$ & 1 & $0.1 \%$ \\
\hline 11 & Rubber \& plastics products & 5 & $0.2 \%$ & 1 & $0.1 \%$ & 4 & $0.3 \%$ \\
\hline 30 & Construction & 4 & $0.1 \%$ & 2 & $0.2 \%$ & 1 & $0.1 \%$ \\
\hline 26 & Production and distribution of electricity & 3 & $0.1 \%$ & 2 & $0.2 \%$ & 1 & $0.1 \%$ \\
\hline 36 & Supporting and auxiliary transport activities & 3 & $0.1 \%$ & 1 & $0.1 \%$ & 2 & $0.1 \%$ \\
\hline 39 & Real estate activities & 3 & $0.1 \%$ & 3 & $0.3 \%$ & 0 & $0.0 \%$ \\
\hline 10 & Pharmaceuticals & 2 & $0.1 \%$ & 1 & $0.1 \%$ & 0 & $0.0 \%$ \\
\hline 15 & Fabricated metal products (no machinery) & 2 & $0.1 \%$ & 2 & $0.2 \%$ & 0 & $0.0 \%$ \\
\hline 2 & Mining and quarrying (energy) & 1 & $0.0 \%$ & 0 & $0.0 \%$ & 0 & $0.0 \%$ \\
\hline 3 & Mining and quarrying (non-energy) & 1 & $0.0 \%$ & 1 & $0.1 \%$ & 0 & $0.0 \%$ \\
\hline 13 & Iron \& steel & 1 & $0.0 \%$ & 0 & $0.0 \%$ & 0 & $0.0 \%$ \\
\hline 14 & Non-ferrous metals & 1 & $0.0 \%$ & 0 & $0.0 \%$ & 0 & $0.0 \%$ \\
\hline \multirow[t]{6}{*}{32} & Hotels \& restaurants & 1 & $0.0 \%$ & 0 & $0.0 \%$ & 1 & $0.1 \%$ \\
\hline & Top 6 business sectors & 2469 & $82.4 \%$ & 737 & $74.2 \%$ & 1335 & $89.4 \%$ \\
\hline & Total for all business sectors & 2998 & $85.2 \%$ & 993 & $80.3 \%$ & 1493 & $88.4 \%$ \\
\hline & Individuals \& non-business organizations & 511 & $14.5 \%$ & 240 & $19.4 \%$ & 191 & $11.3 \%$ \\
\hline & Patents held by non-classified business firms & 11 & $0.3 \%$ & 4 & $0.3 \%$ & 5 & $0.3 \%$ \\
\hline & $\begin{array}{l}\text { Total, including double counting for co- } \\
\text { patenting }\end{array}$ & 3520 & & 1237 & & 1689 & \\
\hline
\end{tabular}

*The share of business sector financial patents is shown in these columns, with the exception of the last 3 rows, where the share of all financial patents is shown. + The sector code is from the OECD-STAN database. 


\begin{tabular}{|c|c|c|c|c|c|c|c|}
\hline Rank & Company & Country & Industry & Entry & $\begin{array}{l}\text { Fin } \\
\text { Pats }\end{array}$ & $\begin{array}{c}\text { All } \\
\text { Pats }\end{array}$ & $\begin{array}{c}\text { Fin } \\
\text { pat } \\
\text { share* }\end{array}$ \\
\hline 1 & IBM & US & Comp serv & pre-1970 & 111 & 14950 & very low \\
\hline 2 & CITICORP & US & Fin $\&$ ins & pre-1970 & 96 & 101 & high \\
\hline 3 & NCR & US & Machinery & pre-1970 & 86 & 1588 & low \\
\hline 4 & FUJITSU & JP & Comp serv & pre-1970 & 85 & 8707 & very low \\
\hline 5 & SIEMENS & $\mathrm{DE}$ & Elec. Eq. & pre-1970 & 76 & 28497 & very low \\
\hline 6 & HITACHI & JP & Comp mach & pre-1970 & 69 & 8733 & very low \\
\hline 7 & SONY & $J P$ & Comm. Eq. & pre-1970 & 47 & 14246 & very low \\
\hline 8 & HEWLETT PACKARD & US & Comp mach & 1981-1990 & 47 & 7312 & very low \\
\hline 9 & SAP & $\mathrm{DE}$ & Comp serv & 1971-1980 & 47 & 1011 & low \\
\hline 10 & SUN MICROSYSTEM & US & Comp mach & 1971-1980 & 40 & 1415 & very low \\
\hline 11 & ATT & US & Post \& tele & pre-1970 & 40 & 5053 & very low \\
\hline 12 & FRANCE TELECOM & FR & Post $\&$ tele & $1981-1990$ & 39 & 1915 & very low \\
\hline 13 & MICROSOFT & US & Comp mach & $1981-1990$ & 38 & 2847 & very low \\
\hline 14 & PITNEY BOWES & US & Comp mach & pre-1970 & 34 & 789 & low \\
\hline 15 & ALCATEL & FR & Comp mach & pre-1970 & 34 & 3847 & very low \\
\hline 16 & NOKIA & FI & Comm. Eq. & pre-1970 & 33 & 6587 & very low \\
\hline 17 & FIRST DATA & US & Fin \& ins & 1991-1995 & 33 & 69 & high \\
\hline 18 & DEUTSCHE POST TELEKOM & $\mathrm{DE}$ & Post $\&$ tele & pre-1970 & 33 & 746 & low \\
\hline 19 & VISA & US & Fin $\&$ ins & pre-1970 & 32 & 65 & high \\
\hline 20 & MASTERCARD INTERNAT. & US & Oth bus & pre-1970 & 30 & 47 & high \\
\hline 21 & LM ERICSSON & SE & Comm. Eq. & pre-1970 & 29 & 6502 & very low \\
\hline 22 & ACCENTURE & US & Comp serv & $1981-1990$ & 27 & 333 & low \\
\hline 23 & LUCENT TECHNOLOGY & US & Comp serv & $1985-1990$ & 26 & 3812 & very low \\
\hline 24 & KONINKLIJKE PTT NEDERLAND & NL & Post \& tele & $1981-1990$ & 25 & 569 & low \\
\hline 25 & DIEBOLD & US & Comp mach & pre-1970 & 25 & 83 & medium \\
\hline 26 & MATSUSHITA ELEC INDUSTRIAL & $\mathrm{JP}$ & Elec. Eq. & pre-1970 & 22 & 16921 & very low \\
\hline 27 & NTT & $\mathrm{JP}$ & Post \& tele & pre-1970 & 22 & 1390 & very low \\
\hline 28 & SWISSCOM & $\mathrm{CH}$ & Post \& tele & 1996-2000 & 21 & 266 & low \\
\hline 29 & TOSHIBA & JP & Comp mach & pre-1970 & 18 & 10047 & very low \\
\hline 30 & AMERICAN EXPRESS & US & Fin $\&$ ins & pre-1970 & 18 & 47 & medium \\
\hline 31 & PHILIPS & NL & Elec. Eq. & pre-1970 & 17 & 4382 & very low \\
\hline 32 & SAGEM & $\mathrm{DE}$ & Instruments & pre-1970 & 17 & 281 & low \\
\hline 33 & NEC & JP & Comp mach & pre-1970 & 16 & 8272 & very low \\
\hline 34 & WESTERN UNION & US & Fin $\&$ ins & pre-1970 & 16 & 20 & high \\
\hline 35 & KODAK & US & Instruments & pre-1970 & 15 & 11187 & very low \\
\hline 36 & GOLDMAN SACHS & US & Fin \& ins & pre-1970 & 14 & 44 & medium \\
\hline 37 & US BANCORP & US & Fin $\&$ ins & pre-1970 & 14 & 16 & high \\
\hline 38 & OMRON & $\mathrm{JP}$ & Instruments & pre-1970 & 13 & 1197 & very low \\
\hline 39 & GEMPLUS & FR & Comm. Eq. & 1981-1990 & 12 & 478 & very low \\
\hline 40 & GIESECKE DEVRIENT & $\mathrm{DE}$ & Printing & pre-1970 & 12 & 665 & very low \\
\hline 41 & AXALTO & FR & Comm. Eq. & pre-1970 & 11 & 261 & low \\
\hline 42 & NOKIA SIEMENS NETWORKS & FI & Comm. Eq. & pre-1970 & 11 & 1318 & very low \\
\hline 43 & BRITISH TELECOM & UK & Post $\&$ tele & $1981-1990$ & 11 & 1908 & very low \\
\hline 44 & SCHLUMBERGER & FR & Instruments & pre-1970 & 11 & 1049 & very low \\
\hline 45 & MOTOROLA & US & Comm. Eq. & pre-1970 & 11 & 5300 & very low \\
\hline 46 & LA POSTE & FR & Post \& tele & $1981-1990$ & 10 & 60 & medium \\
\hline 47 & SUMITOMO MITSUI BANKING & $\mathrm{JP}$ & Fin $\&$ ins & pre-1970 & 10 & 32 & medium \\
\hline 48 & METAVANTE & US & Comp serv & pre-1970 & 10 & 14 & high \\
\hline 49 & OKI & $\mathrm{JP}$ & Elec. Eq. & pre-1970 & 10 & 1026 & very low \\
\hline 50 & EBAY & US & Comp serv & 1991-1995 & 10 & 39 & medium \\
\hline 51 & GE CAPITAL & US & Fin $\&$ ins & pre-1970 & 10 & 27 & medium \\
\hline 52 & ELECTRONIC DATA SYSTEM & US & Comp serv & pre-1970 & 10 & 148 & low \\
\hline
\end{tabular}

* High:>50\%; Medium:10-50\%; Low: 3-10\%; Very low: 0-3\% 


\begin{tabular}{|c|c|c|c|c|c|c|c|}
\hline & \multicolumn{3}{|c|}{$\begin{array}{c}\text { All patents } \\
18,523 \text { observations\#\# }\end{array}$} & \multirow{2}{*}{$\begin{array}{l}\text { T-test } \dagger \\
\text { fin pat vs } \\
\text { all other }\end{array}$} & \multicolumn{3}{|c|}{$\begin{array}{l}\text { Financial patents } \\
\text { 3,298 observations }\end{array}$} \\
\hline & mean & $s d$ & median & & mean & $s d$ & median \\
\hline & \multicolumn{7}{|c|}{ Indicators of Prior Art Base } \\
\hline Inventors & 2.44 & 1.79 & 2.0 & & 2.53 & 2.08 & 2.0 \\
\hline Non-patent literature references & 0.49 & 1.4 & 0.0 & -- & 0.46 & 1.13 & 0.0 \\
\hline Backward citations to patents & 3.75 & 2.98 & 3.0 & --- & 3.34 & 3.27 & 3.0 \\
\hline Backward citations per inventor & 2.28 & 2.32 & 1.7 & & 2.05 & 2.45 & 1.3 \\
\hline XY Type backward citations & 0.88 & 1.6 & 0.0 & --- & 0.87 & 1.44 & 0.0 \\
\hline XY Type backward citations per inventor & 0.51 & 1.06 & 0.0 & & 0.53 & 1.03 & 0.0 \\
\hline \multirow[t]{2}{*}{ Citation Lag in Months @ } & 63.6 & 42.7 & 52.5 & --- & 59.5 & 37.0 & 50.0 \\
\hline & \multicolumn{7}{|c|}{ Indicators of Patent Value } \\
\hline Number of claims & 14.89 & 12.77 & 11 & ++ & 21.78 & 17.78 & 17 \\
\hline Technological classes & 7.16 & 6.96 & 6.0 & --- & 5.77 & 4.61 & 4.0 \\
\hline Patent family size (worldwide equivalents) & 11.03 & 74.05 & 6.0 & & 11.40 & 30.54 & 6.0 \\
\hline Continuations rate & 0.05 & 0.21 & 0.0 & & 0.05 & 0.21 & 0.0 \\
\hline Designated countries & 11.95 & 9.10 & 9.0 & & 14.50 & 9.88 & 18.0 \\
\hline Application via PCT route (dummy) & 0.40 & 0.49 & 0.0 & +++ & 0.44 & 0.50 & 0.0 \\
\hline Forward citations after 3 years & 0.41 & 0.97 & 0.0 & +++ & 0.67 & 1.81 & 0.0 \\
\hline HTT Composite Index & 0.00 & 0.54 & -0.1 & +++ & 0.12 & 0.65 & -0.1 \\
\hline \multirow[t]{2}{*}{ Value from Patval survey (1000s euros) \# } & 11,083 & 65,580 & 650 & --- & 1,523 & 2,791 & 200 \\
\hline & \multicolumn{7}{|c|}{ Status } \\
\hline Decision reached & 0.760 & & & & 0.580 & & \\
\hline Granted, conditional on decision & 0.640 & & & & 0.341 & & \\
\hline Refused,conditional on decision & 0.033 & & & & 0.071 & & \\
\hline Withdrawn, conditional on decision & 0.327 & & & & 0.588 & & \\
\hline Grant lag in years & 3.91 & 1.78 & 3.59 & & 5.10 & 2.23 & 4.77 \\
\hline Opposition if granted $\ddagger$ & 0.065 & & & ++ & 0.090 & & \\
\hline
\end{tabular}

Notes:

$\dagger$ T-test for the hypothesis that the mean for financial patents differs from that for all patents. Significant at $1 \%(+++), 5 \%(++)$, or $10 \%(+)$ level if the mean is larger; similarly for smaller but with a minus (-). Before testing, all variables have bee

@ Computed for nonzero lags only. Numbers of observations are 1077 and 833.

\# Computed for patents that were covered by the PATVAL survey only. Numbers of observations are 5 and 8,281.

$\ddagger$ Computed for granted patents only. Numbers of observations are 9003 and 736; for grant prior to 2001, they are 8883 and 642.

\#\# This is a $1 \%$ sample of all patents. 
Table 4: Probability of decision, grant, and opposition conditional on grant 1978-2005

Financial patents vs. a one per cent sample of other patents

\begin{tabular}{|c|c|c|c|c|c|c|c|c|c|}
\hline \multirow[t]{2}{*}{ Dependent variable } & \multicolumn{3}{|c|}{ Decision } & \multicolumn{3}{|c|}{$\begin{array}{c}\text { Grant conditional on } \\
\text { decision }\end{array}$} & \multicolumn{3}{|c|}{$\begin{array}{c}\text { Opposition conditional } \\
\text { on grant by } 2003\end{array}$} \\
\hline & $\begin{array}{c}\text { Marginal } \\
\text { effect }\end{array}$ & s.e. & & $\begin{array}{c}\text { Marginal } \\
\text { effect }\end{array}$ & s.e. & & $\begin{array}{c}\text { Marginal } \\
\text { effect }\end{array}$ & s.e. & \\
\hline $\mathrm{D}$ (financial patent) & -0.054 & 0.008 & $* * *$ & -0.240 & 0.014 & $* * *$ & 0.018 & 0.011 & $*$ \\
\hline Inventors $(\log )$ & -0.050 & 0.006 & $* * *$ & 0.017 & 0.011 & $*$ & 0.001 & 0.006 & \\
\hline Non-patent literature references $(\log )$ & 0.013 & 0.006 & $* *$ & -0.042 & 0.009 & $* * *$ & -0.016 & 0.006 & $* * *$ \\
\hline Backward citations to patents (log) & 0.064 & 0.005 & $* * *$ & 0.077 & 0.009 & $* * *$ & 0.005 & 0.005 & \\
\hline XY Type backward citations (log) & -0.015 & 0.005 & $* * *$ & -0.104 & 0.008 & $* * *$ & 0.016 & 0.005 & $* * *$ \\
\hline Claims (log) & -0.055 & 0.005 & $* * *$ & -0.091 & 0.007 & $* * *$ & 0.007 & 0.004 & \\
\hline Technological classes $(\log )$ & -0.010 & 0.005 & $* *$ & -0.083 & 0.008 & $* * *$ & -0.010 & 0.004 & $* *$ \\
\hline Family size $(\log )$ & 0.006 & 0.005 & & 0.369 & 0.016 & $* * *$ & 0.020 & 0.005 & $* * *$ \\
\hline D (continuation) & -0.181 & 0.020 & $* * *$ & -0.085 & 0.026 & $* * *$ & 0.021 & 0.012 & $* *$ \\
\hline Designated countries (log) & -0.033 & 0.003 & $* * *$ & -0.017 & 0.006 & $* * *$ & 0.026 & 0.005 & $* * *$ \\
\hline $\mathrm{D}(\mathrm{PCT}$ route $)$ & -0.086 & 0.006 & $* * *$ & -0.143 & 0.011 & $* * *$ & -0.018 & 0.006 & $* * *$ \\
\hline Forward citations after 3 years $(\log )$ & -0.014 & 0.007 & $* *$ & 0.051 & 0.009 & $* * *$ & 0.026 & 0.005 & $* * *$ \\
\hline Number of observations (number=1) & 23,01 & $(16,689$ & & 16,689 & $(10,034$ & & & $(705)$ & \\
\hline Pseudo R-squared & & 454 & & & 173 & & & 051 & \\
\hline
\end{tabular}

Marginal effects and their robust standard errors are shown. Significance at $1 \% * * * 5 \% * * 10 \% *$. 
Table 5: Probability of decision, grant, and opposition conditional on grant 1978-2005 Financial patents only

2998 observations for 1021 patentees (1718 decisions, 618 grants, 53 oppositions out of 553 pre-2001 grants) Grant conditional on Opposition

Dependent variable

Decision decision conditional on grant

Marginal s.e. Marginal s.e. Marginal s.e.

$\log$ (stock of EP patents) +

Owner characteristics

Log (stock of XY backward cites) +

$\begin{array}{ll}-0.079 & 0.045 *\end{array}$

0.157

0.059

0.031

* $\quad-0.051$

0.059

$* * *$

$-0.036$

0.032

$\log$ (stock of forward cites per patent)+

$-0.030$

0.046

0.047

0.045

0.108

0.034

$-0.001$

0.014

$\mathrm{D}$ (small firm)

0.108

0.042

$-0.048$

0.077

$-0.029$

0.038

D (medium firm)

0.039

0.039

$* *$

0.003

0.064

0.040

0.055

Founded 1981-1995

0.014

0.049

$-0.031$

0.073

0.072

0.071

Founded after 1995

$-0.053$

0.042

0.054

$-0.022$

0.020

Software sector

$-0.009$

0.044

0.095

0.074

$-0.051$

0.017

Other business services

$-0.002 \quad 0.056$

0.026

0.058

* $\quad-0.012$

0.026

Post \& telecommunications

$\begin{array}{ll}0.070 & 0.049\end{array}$

0.086

0.072

$-0.032$

0.020

Finance \& insurance

$-0.034$

0.067

$-0.119$

0.076

0.011

0.027

Computing equipment

$\begin{array}{ll}-0.075 & 0.075\end{array}$

0.254

0.060

* 0.016

0.041

Communication equipment

$\begin{array}{ll}-0.040 & 0.037\end{array}$

0.093

0.064

$* * *$

0.029

0.036

US owner

$-0.161$

0.060

$-0.130$

0.066

0.032

0.050

Japanese owner

$\begin{array}{ll}0.105 & 0.049\end{array}$

$-0.128$

0.066

** $\quad-0.022$

0.027

German owner

$\begin{array}{ll}0.085 & 0.053\end{array}$

0.076

0.066

* $\quad-0.008$

0.031

French owner

$-0.005 \quad 0.061$

0.081

0.084

0.110

0.074

$\begin{array}{ll}0.041 \quad 0.048 \\ 0.014 & 0.052\end{array}$

UK owner

$5.5 \quad 0.065$ *

0.027

0.094

$0.014 \quad 0.052$

Chi-squared (2) size

$\begin{array}{ll}1.1 & 0.593 \\ 8.5 & 0.209\end{array}$

0.9

0.097

1.9

0.389

Chi-squared (2) founding year

$\begin{array}{ll}8.5 & 0.209\end{array}$

1.1

0.637

$5.2 \quad 0.076$

25.1

0.567

Chi-squared (6) sector dummies

$21.0 \quad 0.001$

18.2

0.000

3.1

0.800

Chi-squared (5) region

$49.9 \quad 0.000$

$* * *$

123.3

0.003

$* * *$

9.2

0.103

Patent characteristics

Log (inventors)

Log (total backward cites)

$-0.053$

0.017
0.018

0.000

$* * *$

31.0

$0.029 * *$

Log (XY backward cites)

0.093

0.018

***

0.015

0.024

0.005

0.015

$-0.025$

0.021

0.120

0.023

$* * *$

0.005

0.020

Log (claims)

$-0.041$

0.017

$-0.089$

0.025

$* * *$

0.021

0.016

0.024

$-0.041$

0.026

$-0.095$

0.031

$* * *$

0.021

0.013

Log (family size)

$-0.093$

0.015

0.239

0.021

$* * * \quad 0.045$

0.014

$-0.009 \quad 0.018$

D (PCT route)

$-0.114$

0.033

0.042

0.019

$-0.069$

0.038

* -0.044

0.016

Log (forward pat cites received in $3 \mathrm{yrs}$ )

Priority year 1986-1990

combined with pre-1986

$\begin{array}{lll}-0.857 & 0.013 * * *\end{array}$

0.046

0.021

$* *$

0.041

0.012

$\begin{array}{ll}0.034 & 0.049\end{array}$

Priority year 1991-1995

Priority year 1996-2000

$-0.9950 .002 * * *$

0.011

0.103

$-0.044$

0.028

$\begin{array}{llll}-0.999 & 0.000 & * * *\end{array}$

$-0.213$

$-0.056$

0.037

no oppositions

Priority year post-2000

Pseudo R-squared

0.302

0.307

0.243

The left out category is a patent owned by a large firm in the rest of the world that was founded before 1981, and that operates in one of the remaining business sectors, with priority year prior to 1986 (prior to 1991 in the first set of columns).

Marginal effects and their standard errors clustered on patentee are shown. Significance at $1 \% * * * 5 \% * * 10 \% *$.

+ These variables are stocks for all the firm's patents as of the priority year of the current patent, constructed using a $15 \%$ depreciatio

\# All patent characteristics excluding the priority year dummies, which control for selection over time. 


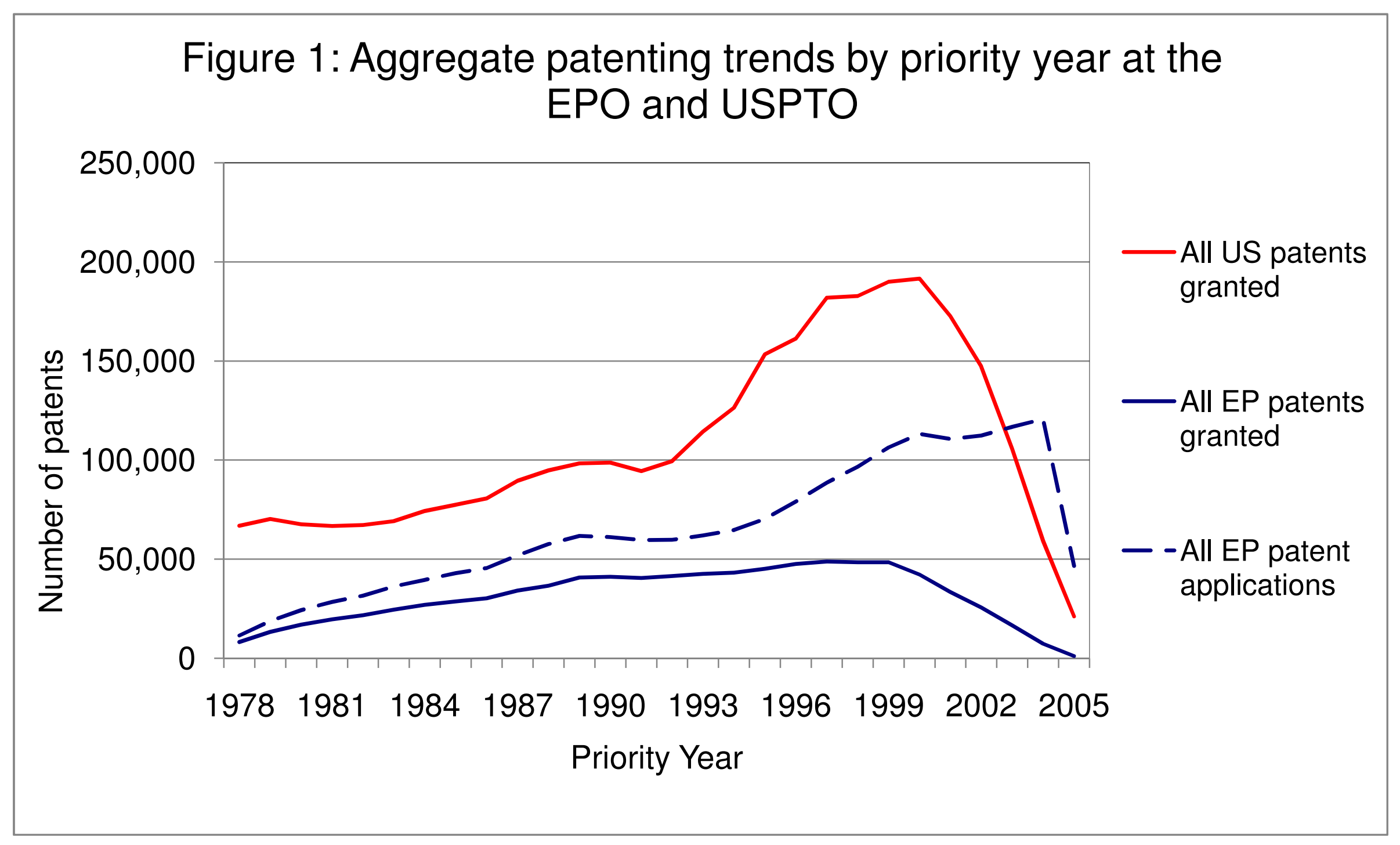




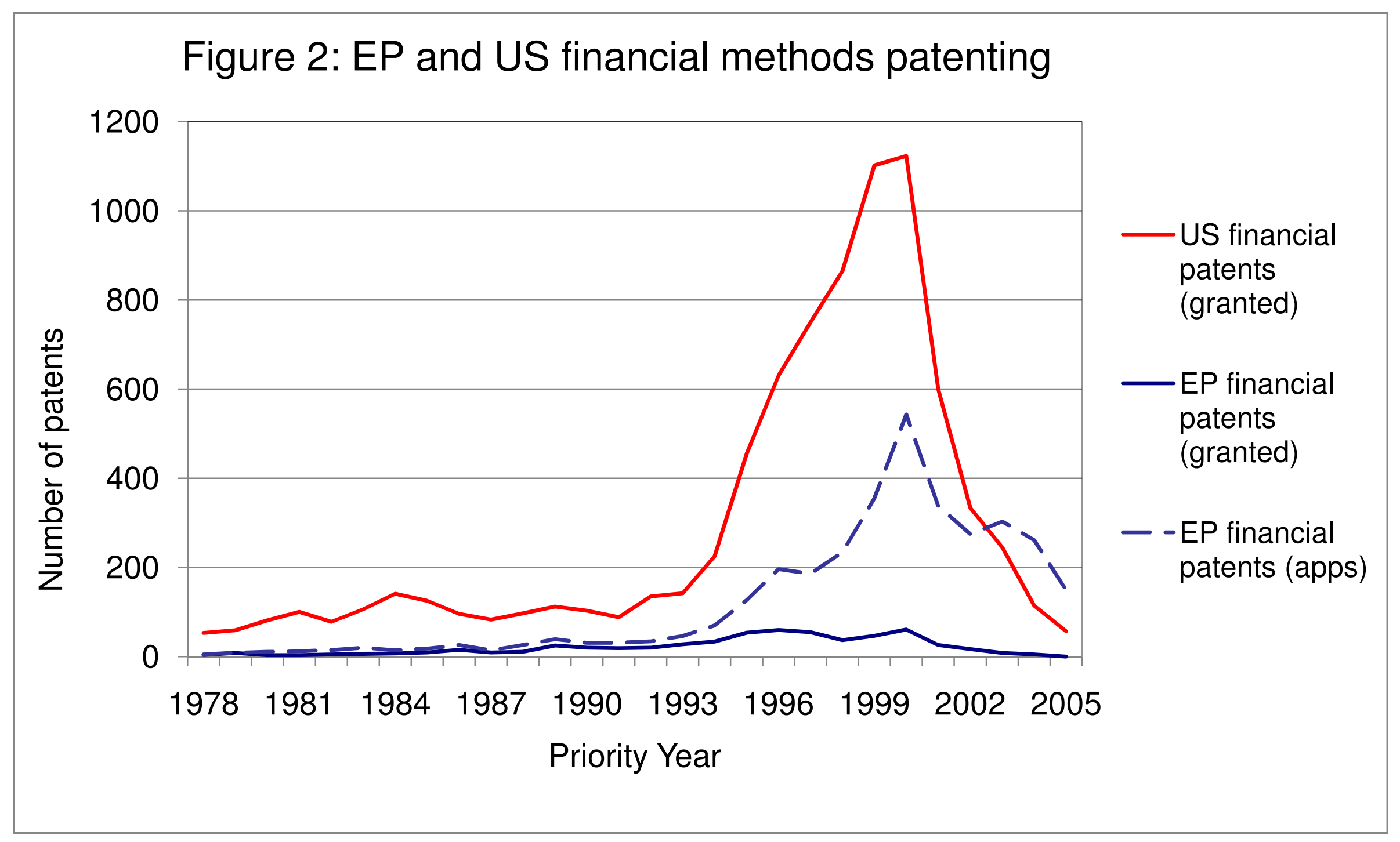




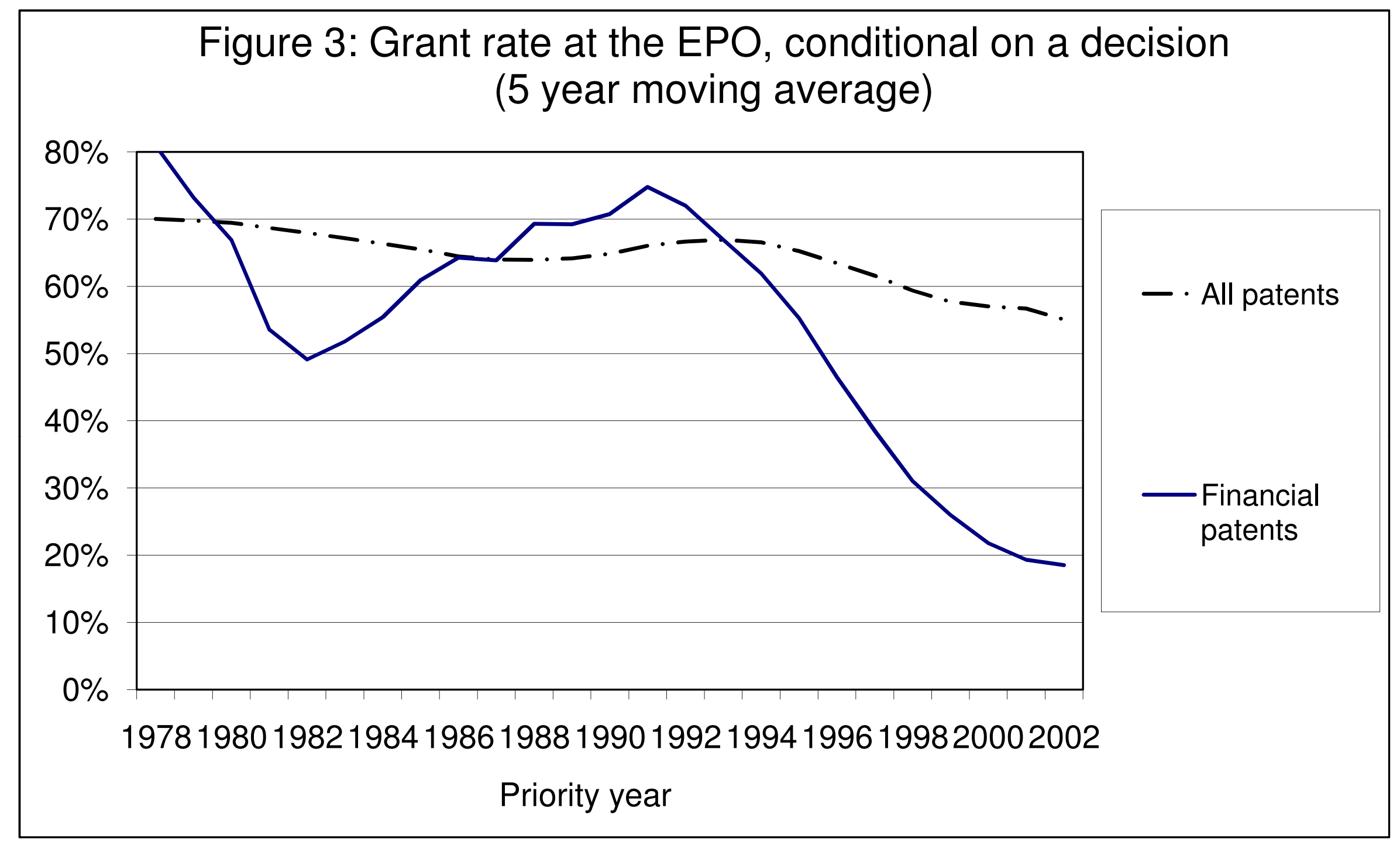




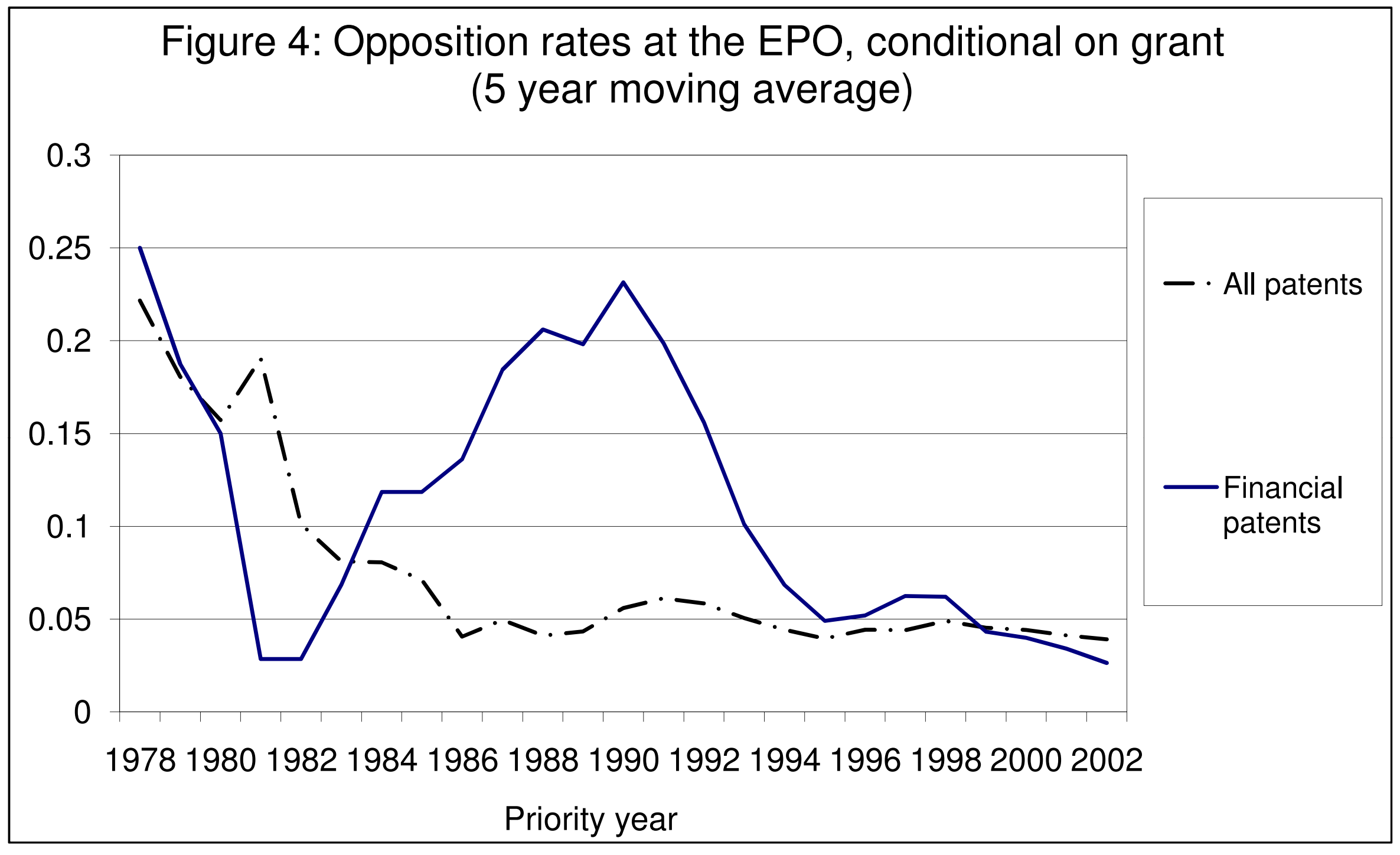

